\title{
Tropical anvil characteristics and water vapor of the tropical tropopause layer: Impact of heterogeneous and homogeneous freezing parameterizations
}

\author{
Jiwen Fan, ${ }^{1}$ Jennifer M. Comstock, ${ }^{1}$ Mikhail Ovchinnikov, ${ }^{1}$ Sally A. McFarlane, ${ }^{1}$ \\ Greg McFarquhar, ${ }^{2}$ and Grant Allen ${ }^{3}$ \\ Received 18 June 2009; revised 8 January 2010; accepted 20 January 2010; published 16 June 2010.
}

[1] Two isolated deep convective clouds (DCCs) that developed in clean-humid and polluted-dry air masses, observed during the Tropical Pacific Warm Pool International Cloud Experiment (TWP-ICE) and U.K. Aerosol and Chemical Transport in Tropical Convection (ACTIVE) campaigns, respectively, are simulated using a three-dimensional cloud-resolving model with size-resolved aerosol and cloud microphysics. We examine the impacts of different homogeneous and immersion freezing parameterizations on the anvil characteristics and the water vapor content (WVC) in the tropical tropopause layer (TTL) for the two DCCs that developed in contrasting environments. The modeled cloud properties such as liquid/ice water path and precipitation generally agree with the available radar and satellite retrievals and in situ aircraft measurements. We find that anvil microphysical properties such as ice number concentration and ice effective radius $\left(r_{e i}\right)$ are sensitive to the homogeneous freezing parameterizations (HomFPs) under both the clean-humid and polluted-dry conditions, while upper level convection and WVC in the TTL air are only sensitive to HomFPs under the polluted-dry condition. Specifically, the cloud anvil with the Koop et al. (2000) relative humidity dependent scheme has up to $50 \%$ and $70 \%$ lower ice number than those with other schemes (temperature dependent) for the clean-humid and polluted-dry cases, respectively. Consequently, the $r_{e i}$ is increased by $20-30 \mu \mathrm{m}$ in both cases. As a result, extinction coefficient of cloud anvils is reduced by over $30 \%$. Anvil size and evolution are also much affected by HomFPs. Higher immersion-freezing rate (Bigg, 1953) leads to a stronger convective cloud due to larger latent heat release resulted from much higher freezing rates, with larger ice water path but less precipitation in both humid and dry conditions. Consequently, the domain-averaged homogeneous freezing rates are enhanced by over $15 \%$. Also, the higher immersion-freezing rate results in over 1.5 times higher ice number concentrations, much reduced $r_{e i}$ in the cloud anvil, and larger anvil size. The moistening effect of deep convection on the TTL clear air is very significant, with increases of a few times relative to the WVC before convection under both humid and dry conditions. Different HomFPs does not make much difference in WVC and upper level convection in the clean-humid case, but in the polluted-dry case, the HomFPs with lower nucleation rates predict about $25 \%$ lower WVC relative to the HomFPs with higher nucleation rates. Under both humid and dry conditions, the Bigg (1953) immersion freezing predicts about $25 \%$ higher WVC relative to the Vali (1975) parameterization, due to stronger transport and the larger anvil area in the domain.

Citation: Fan, J., J. M. Comstock, M. Ovchinnikov, S. A. McFarlane, G. McFarquhar, and G. Allen (2010), Tropical anvil characteristics and water vapor of the tropical tropopause layer: Impact of heterogeneous and homogeneous freezing parameterizations, J. Geophys. Res., 115, D12201, doi:10.1029/2009JD012696.

\footnotetext{
${ }^{1}$ Department of Climate Physics, Pacific Northwest National Laboratory, Richland, Washington, USA.

${ }^{2}$ Department of Atmospheric Sciences, University of Illinois at UrbanaChampaign, Urbana, Illinois, USA.

${ }^{3}$ School of Earth, Atmospheric and Environmental Sciences, University of Manchester, Manchester, UK.

Copyright 2010 by the American Geophysical Union. 0148-0227/10/2009JD012696
}

\section{Introduction}

[2] Deep convective systems and their associated cloud anvils dominate the rainfall and cloudiness over much of the tropics [Futyan and Del Genio, 2007]. They affect the radiation budget and moisture perturbation in the tropics, which, in turn, affects the large-scale circulation. It has been found that the radiative forcing of a modeled convective cloud by a 
cloud-resolving model (CRM) generally increases with increasing aerosols, and the increase appears to have a stronger correlation with changes in cloud coverage than other cloud properties (e.g., particle effective radius) [Wang, 2005a; Ekman et al., 2007]. The evolution and lifetime of convective systems has great implications for the radiative and hydrological budgets. Recently, satellite radar observations were used to observe the convective life cycle and find a correlation between the convective intensity and the lifetime, size, and depth of the resultant anvil [Futyan and Del Genio, 2007]. Certainly, the net effect of convective systems on the radiation budget also depends on cloud microphysical properties such as hydrometeor shapes and sizes [Stephens and Tsay, 1990; Takano et al., 1992]. The microphysical properties of tropical anvils are related to their parent deep convective turrets, and this relationship has been of strong interest in recent years [Frederick and Schumacher, 2008; McFarquhar et al., 2007; Connolly et al., 2007, 2008].

[3] In addition to their radiative and hydrological impacts, deep convective clouds (DCCs) potentially influence the water vapor content (WVC) entering the stratosphere through convective overshoots [Sherwood et al., 2003]. The tropical tropopause layer (TTL), the layer between the main convective outflow $(\sim 12-14 \mathrm{~km})$ and the cold point tropopause $(\sim 17-19 \mathrm{~km})$, acts as a "gate to the stratosphere." The WVC in the TTL affects Earth's climate by modifying the radiative heating rates and atmospheric chemistry by providing a source of $\mathrm{OH}^{-}$radicals, which are the main oxidizing agents in the atmosphere and, as such, affect the rates of production and loss of many species [Fueglistaler et al., 2009]. Therefore understanding what factors significantly affect the WVC in the TTL is vitally important. The role of deep convection in transporting aerosol, chemical species, and water vapor to the upper tropical troposphere from the planetary boundary layer (PBL) is crucial to climate science [Dickerson et al., 1987], yet the effect of convection on the TTL water vapor budget is currently not well quantified [Fueglistaler et al., 2009]. A number of observational and modeling studies suggest a net moistening effect on the TTL [e.g., Corti et al., 2008; Jensen et al., 2007; Grosvenor et al., 2007], while some other studies found evidence that convective overshoots induce drying [Sherwood and Dessler, 2000; Kuang and Bretherton, 2004]. Clearly, more measurements and modeling studies are needed to constrain the effect of DCCs on the TTL WVC. Moreover, most previous modeling studies were performed using CRMs with bulk microphysics schemes including certain simplified ice nucleation mechanisms. Since the latent heat released from heterogeneous and homogeneous freezing processes could enhance convective strength [Khain et al., 2005], and potentially affect cloud properties and the transport of water vapor from lower levels to the TTL, the impact of different freezing parameterizations on WVC in the TTL needs to be explored.

[4] The ice nucleation mechanism can have a significant impact on the microphysical properties of cloud anvils in DCCs. Homogenous freezing is the major source of ice crystals in cloud anvils and cirrus clouds [Heymsfield et al., 2005]. At temperatures between 238 and $233 \mathrm{~K}$, cloud droplets of diameter several microns or larger will freeze spontaneously, and droplets smaller than $1 \mu \mathrm{m}$ will freeze at lower temperatures [Sassen and Dodd, 1988; Heymsfield and Sabin, 1989; Heymsfield et al., 2005]. A few parameterizations of homo- geneous nucleation rates have been developed based on laboratory experiments or field measurements [e.g., Bigg, 1953; Heymsfield and Miloshevich, 1993; Koop et al., 2000] (see section 3.2 for details). In many models, all droplets are assumed to freeze instantaneously at temperatures below 235 K [e.g., Khain et al., 2004; Tao et al., 2004; Fan et al., 2007a, 2007b; Zhang et al., 2007]. Different homogeneous freezing parameterizations (HomFPs) applied in the numerical models could change the formed ice crystal number due to different freezing rates. The impacts of the different HomFPs on these anvil properties have not been investigated.

[5] Although homogenous freezing is very important in forming anvil cirrus clouds [Ekman et al., 2007], the ice crystals in the mixed-phase clouds at relatively lower levels are formed through heterogeneous freezing, which can potentially affect the microphysical properties and radiative impact of ice clouds at higher levels [Heymsfield and Sabin, 1989; DeMott et al., 1997; Heymsfield et al., 2005]. The parameterizations of the heterogeneous nucleation mechanisms such as immersion-freezing are not even consistent in magnitude [Archuleta et al., 2005]. The commonly used Vali [1975] immersion-freezing parameterization gives much lower freezing rates than Bigg [1953] [Khain et al., 2000]. The effect of these heterogeneous nucleation parameterizations on the cloud anvils and the homogenous freezing process at higher levels is still not well constrained, although some studies indicated that heterogeneously formed ice crystals may significantly alter the homogenous freezing process [Heymsfield et al., 2005; Ekman et al., 2007].

[6] Two recent major field campaigns, the Tropical Pacific Warm Pool International Cloud Experiment (TWP-ICE) [May et al., 2009], funded by the U.S. Department of Energy's Atmospheric Radiation Measurement (ARM) program, and the U.K. Aerosol and Chemical Transport in Tropical Convection (ACTIVE) campaign [Vaughan et al., 2008], were designed to provide well-focused data sets to address scientific questions related to tropical DCCs. We examine the anvil characteristics of two isolated DCCs observed during the TWP-ICE and ACTIVE campaigns. These two cases provide unique environmental conditions in which to explore the impacts of DCCs; one occurs under polluted-dry conditions, while the other occurs under clean-humid conditions. We explore the impacts of different immersion and homogeneous freezing parameterizations on anvil properties and WVC in the TTL by combining model simulations with observations from aircraft and remote-sensing instruments. The effects of the immersion-freezing parameterizations on the homogenous freezing process are also examined. A CRM referred to as SAM-SBM [Fan et al., 2009], i.e., the System for Atmospheric Modeling (SAM) [Khairoutdinov and Randall, 2003] coupled with a spectral-bin microphysics scheme (SBM) based on that of Khain et al. [2004], is used to simulate the DCCs. Model simulations are evaluated using aircraft in situ observations and a radar simulator that has been coupled with SAM-SBM to facilitate the comparisons with remote-sensing measurements [Fan et al., 2009].

\section{Case Descriptions and Observations}

[7] The thunderstorms considered in this study occurred over the Tiwi Islands, north of Darwin, Australia, on 16 November 2005 during ACTIVE (referred to hereafter as 
NOV16) and on 6 February 2006 during TWP-ICE (referred to hereafter as FEB06). The ACTIVE campaign was conducted during the 2005-2006 wet season (NovemberFebruary) in Darwin, Australia $\left(12.47^{\circ} \mathrm{S}, 130.85^{\circ} \mathrm{E}\right)$, and used two aircraft: the Dornier $228-101$ operated by the Natural Environment Research Council (NERC) Airborne Research and Survey Facility, and the Grob G520T Egrett aircraft operated by Airborne Research Australia. Instrumentation on the Dornier measured the aerosol and chemical background of the boundary layer and lower free troposphere between 100 and $4000 \mathrm{~m}$, while the Egrett measured cirrus cloud microphysics and outflow from deep convection up to an operational ceiling of $15 \mathrm{~km}$. TWP-ICE was carried out in the same region as ACTIVE from January to February 2006 during the Australian monsoon. Two of the five research aircraft (the Scaled Composite's Proteus, carrying the ARM Unmanned Aerial Vehicle (UAV; now known as the ARM Aerial Facility) suite of instruments and the Airborne Research Australia's (ARA's) Egrett) were high-altitude aircraft capable of in situ measurements in the anvil outflow up to $\sim 15 \mathrm{~km}$.

[8] Thunderstorms over the Tiwi Islands are among the world's tallest, with cloud tops often reaching $20 \mathrm{~km}$ [Crook, 2001]. These regularly occurring afternoon thunderstorms in the premonsoon and monsoon break periods which are colloquially known as "hectors," produce massive anvils and heavy rainfall [Wilson et al., 2001] and have been the subject of many observational and modeling studies [e.g., May et al., 2009; Allen et al., 2008; Connolly et al., 2006]. These hectors are strongly correlated to the diurnal heating [Crook, 2001], since the synoptic-scale changes are small in magnitude [Wilson et al., 2001]. This provides a natural laboratory-type situation where changes in storm evolution can be easily isolated from large-scale conditions [Wilson et al., 2001]. NOV16 and FEB06 are two hector storms with contrasting atmospheric conditions [Allen et al., 2008]. The former occurred under the premonsoon conditions and during a period of intense local and regional biomass burning. The low-level easterly flow around Darwin brought polluted air masses containing biomass burning products from the largescale land clearing burning over Arnhem Land [Vaughan et al., 2008]. The middle-tropospheric air was especially dry in this case [Connolly et al., 2008]. A single-cell thunderstorm formed around 0540 UTC on NOV16. Its anvil soon detached and was advected southward by the prevailing northerly wind at $150-200 \mathrm{hPa}$. The contrasting case on FEB06 occurred during a monsoon break period and the airflow was strongly easterly. Air masses were clean and humid [May et al., 2009]. An isolated single-cell storm broke out around 0450 UTC, with radar echoes reaching $17 \mathrm{~km}$. The anvil was advected northwestward over the next $2 \mathrm{~h}$.

[9] Extensive in situ and remote-sensing measurements are used to constrain simulations and validate model results. Aerosol properties measured on the Dornier and microphysical properties of anvils from the Egrett for NOV16 and Proteus for FEB06 are used in this study. Aerosol instruments on board the Dornier included (1) a Droplet Measurement Technologies (DMT) ultrahigh sensitivity aerosol spectrometer (UHSAS), measuring dry fine mode aerosol size spectra of 55-800 nm; (2) a prototype DMT aerosol spectrometer probe (ASP, $0.21-4.5 \mu \mathrm{m}$ ), and (3) a wing-mounted forward scattering spectrometer probe (FSSP-100, 0.5-32 $\mu \mathrm{m}$ ) for measuring coarse aerosols. The Proteus was equipped with a cloud aerosol spectrometer (CAS) sizing between 0.5 and $50 \mu \mathrm{m}$, a cloud droplet probe (CDP, 2 to $50 \mu \mathrm{m}$ ), a cloud imaging probe (CIP, nominally sizing between 25 to $1550 \mu \mathrm{m})$, a cloud particle imager (CPI, 15-1500 $\mu \mathrm{m}$ ), a Nevzorov probe measuring liquid water content (LWC), and a cloud spectrometer and impactor probe (CSI) measuring total water content (TWC), the sum of LWC and ice water content (IWC). A CAS, CIP, and CPI were also mounted on Egrett to measure anvil microphysical properties for NOV16.

[10] Ground-based measurements from the C-band polarimetric/Doppler meteorological radar system (C-POL) (5.67 GHz) [Keenan et al., 1998] located at Gunn Point, which typically scanned with a radius of $140 \mathrm{~km}$ covering Tiwi Islands, are also used to evaluate the model performance at simulating the properties of the deep convection. For FEB06, measurements from the upward looking NASA $94 \mathrm{GHz}$ airborne cloud radar (ACR) $(94 \mathrm{GHz})$ on board the Twin Otter aircraft, which flew under the cloud anvil, are further used to evaluate the simulated anvil clouds. We also compare the model results with the Minnis Satellite Cloud Products Using the Visible Infrared Solar-Infrared Split Window Technique (VISST) algorithm [Minnis et al., 2006]. The data streams are pixel-level $(4 \mathrm{~km})$ retrievals and averages on a $0.3^{\circ}$ or $0.5^{\circ}$ latitude-longitude grid.

\section{Descriptions of Model and Numerical Experiments}

\subsection{SAM-SBM}

[11] The SAM-SBM used in this study is based on the model described by Fan et al. [2009]. Here some highlights and new modifications are presented. SAM has the dynamical framework of a large-eddy simulation (LES) model and solves the equations of motion using the anelastic approximation [Khairoutdinov and Randall, 2003]. The finite difference representation of the model equations uses the Arakawa C staggering, with stretched vertical and uniform horizontal grids. The advection and diffusion of momentum are second-order accurate. Advection of all scalar prognostic variables is done using a monotonic and positive-definite advection scheme [Smolarkiewicz and Grabowski, 1990].

[12] The SBM [Khain et al., 2004] has been applied to various dynamical frameworks and to simulate DCCs in many prior studies [e.g., Khain et al., 2005, 2008; Fan et al., 2007a, 2007b; Tao et al., 2007; Lynn et al., 2005a, 2005b]. The model is based on solving a system of equations for eight number size distributions for water drops, ice crystals (columnar, plate-like and dendrites), snowflakes, graupel, hail/frozen drops, and cloud condensation nuclei (CCN). An additional size distribution (SD) has been added for ice nuclei (IN) to investigate the IN effects on clouds [Fan et al., 2009]. Each SD is represented by 33 mass doubling bins. Cloud droplets and raindrops are separated by the bin radius of 100 um. The smallest bin for droplets is $2 \mu \mathrm{m}$ in radius. All relevant microphysical processes/interactions including droplet nucleation, primary and secondary ice generation, condensation/evaporation of drops, deposition/sublimation of ice particles, freezing/melting, and mutual collisions between the various hydrometeors are calculated explicitly. The dependence of the collision efficiencies on height, as well as effects of turbulence on the rate of collisions is taken into account 
[Khain et al., 2005]. An updated remapping scheme has been used that conserves three moments of the hydrometeor SDs (concentration, mass, and radar reflectivity) to reduce numerical spectral broadening [Khain et al., 2008]. Scavenging $\mathrm{CCN}$ by precipitation is not considered, and there is no flux of $\mathrm{CCN}$ from the boundaries. The regeneration of the $\mathrm{CCN}$ from droplet evaporation is considered, and the total particles recycled from droplet evaporation for each time step are counted and then distributed over the $\mathrm{CCN}$ spectra by keeping the shape of the initial CCN size distribution [Fan et al., 2009]. In literature, an alternative approach has been used so that $90 \%$ of the released aerosols from evaporation are introduced into the accumulation mode assuming growth due to in-cloud processing and $10 \%$ of them are put back to the coarse mode [Engström et al., 2008]. The calculations of saturation vapor pressures with respect to water and ice are replaced with formula from Murphy and Koop [2005], which predicts lower saturation vapor pressures at $\mathrm{T}<273 \mathrm{~K}$ compared with the original formula developed by Tzivion et al. [1989]. Details about the radar simulator used in this study are given by Fan et al. [2009].

\subsection{Homogeneous Nucleation and Immersion-Freezing Parameterizations}

[13] A few homogeneous freezing parameterizations such as those of Koop et al. [2000] and Bigg [1953] are commonly used in the model simulations. However, drop freezing described by Koop et al. [2000] is both temperature and relative humidity dependent, while it is only temperaturedependent in many other parameterizations [e.g., Bigg, 1953]. The commonly used heterogeneous freezing parameterizations such as those of Bigg [1953] and Vali [1975] have very large differences in temperature dependency [Khain et al., 2000]. To explore the impact of different heterogeneous and homogeneous ice nucleation parameterizations on anvil properties and WVC in the TTL, we incorporated them into the SAM-SBM in this study. A brief description of these schemes is provided here. Additional information can be found in corresponding references.

[14] Koop et al. [2000] (referred to as KOOP hereafter) developed a homogeneous freezing parameterization based on laboratory data giving the nucleation rate $(J)$ as a function of water activity and temperature (independent of the nature of solute). This scheme has been widely used in recent years for cirrus cloud simulations [e.g., Jensen et al., 2005; Jensen and Ackerman, 2006; Kärcher, 2003; Lin et al., 2002]. Water activity of a solution is defined as the ratio between the water vapor pressure of the solution and of pure water under the same conditions. It is equivalent to $\mathrm{RH}$ for the solution droplets in equilibrium in the atmosphere. The ice nucleation rate $(J)$ is calculated by Koop et al. [2000, Table 1, equations $1-7]$. Although the scheme was developed based on the freezing of hazy aerosols, it should work for diluted droplets (T. Koop, personal communication, October 2009) and it has been applied to the freezing of cloud droplets in the cloud simulations of Heymsfield et al. [2005]. The calculation of water activity for supercooled cloud droplets in this study was taken from Heymsfield et al. [2005], i.e., it is calculated based on water vapor pressure and the saturated vapor pressure over supercooled liquid that is derived using the saturated vapor pressure over ice divided by the activity of water in equilibrium with ice (A. Hemysfield, personal communica- tion, October 2009). The homogeneous freezing parameterization from Heymsfield and Miloshevich [1993] (referred to as HEYM) is based on the statistical molecular approach of Eadie [1971], applied to both cloud droplets and solution aerosol drops and tested against aircraft observations in wave clouds. In this parameterization, $J$ depends on temperature only [Heymsfield and Miloshevich, 1993, equation 1], but includes the depression of the freezing point due to solute and curvature effects. Note that these effects are only significant when droplets are less than 1-2 $\mu \mathrm{m}$. Another parameterization used in this study is from the stochastic hypothesis formulated by Bigg [1953] based on laboratory experiments of the freezing of water drops $(D>10 \mu \mathrm{m})$, in which $J$ also depends on temperatures only (referred to as BIGG). The equation for calculating $J$ is presented here since Bigg [1953] could be hard to access: $J=-a \exp \left(-b T_{c}\right)$, where $a=10^{-4} \mathrm{~s}^{-1}$ $\mathrm{g}^{-1}, b=0.66\left({ }^{\circ} \mathrm{C}\right)^{-1}$, and $T_{c}$ is temperature $\left({ }^{\circ} \mathrm{C}\right)$. BIGG can serve as both an immersion and homogeneous freezing parameterization, depending on temperature regimes. At $T<$ $237 \mathrm{~K}$, this parameterization is used for homogeneous ice nucleation in many models [e.g., Reisner et al., 1998; Reisin et al., 1996; Khain et al., 2004]. The same formula is also used as an immersion-freezing parameterization at $T>237 \mathrm{~K}$ [Khain et al., 2000]. The freezing rate from this scheme increases rapidly with height above the freezing level, and it is notorious for producing enormous amounts of small ice crystals in the mixed-phase cloud temperature regimes [Khain et al., 2000]. Another commonly used immersionfreezing parameterization is from Vali [1975] (referred to as VALI): $N_{\text {im }}=N_{\text {imo }}\left(0.1 T_{c}\right)^{\gamma}$, where $N_{\text {im }}$ is a number of active nuclei per unit volume of liquid water, $N_{i m 0}=10^{7} \mathrm{~m}^{-3}, \gamma=$ 4.4. This formula reveals much less temperature dependence of active IN than BIGG. Therefore the ice production from this scheme is much less effective [Ovtchinnikov and Kogan, 2000; Khain et al., 2000].

[15] To demonstrate differences in the above mentioned homogeneous nucleation parameterizations, we plot the freezing probabilities in the model integration time step (i.e., $2 \mathrm{~s}$ ) as a function of temperature and relative humidity with respect to water $(R H)$ for droplets with diameters of 4 and $10 \mu \mathrm{m}$ (Figure 1). For KOOP, the freezing probability depends on both temperature and $R H$ (Figure 1, top). Over the homogeneous freezing temperature range $(T<236 \mathrm{~K})$, freezing from KOOP is not possible when $R H$ is less than $80 \%$, even for $10 \mu \mathrm{m}$ droplets. The freezing probability is close to 1.0 when $R H$ is $100 \%$ and it is very similar to HEYM, meaning that freezing of droplets would be instantaneously inside clouds. When $R H$ is less than $98 \%$ that could happen in the entrainment and downdraft region, the freezing probability is very low by KOOP at relatively warmer temperatures $(T>232 \mathrm{~K})$. Therefore those droplets would evaporate completely before freezing happens. A recent experimental study from Kuhn et al. [2009] showed the low freezing rate (about $10^{-3} \mathrm{~s}^{-1}$ ) for $4 \mu \mathrm{m}$ droplets at low temperature about $235 \mathrm{~K}$. However, those droplets will freeze and become ice crystals in HEYM since freezing only depends on temperature and the freezing probability is high at $T<236 \mathrm{~K}$ (Figure 1, middle). The freezing probability is close to 1.0 even for small droplets $(4 \mu \mathrm{m})$. BIGG also has freezing probabilities as low as KOOP (when $R H$ is less than $100 \%$ ) at the relatively warmer temperatures (Figure 1, bottom). The freezing probability is less than 0.1 for $4 \mu \mathrm{m}$ droplets at $T>$ 
(a)
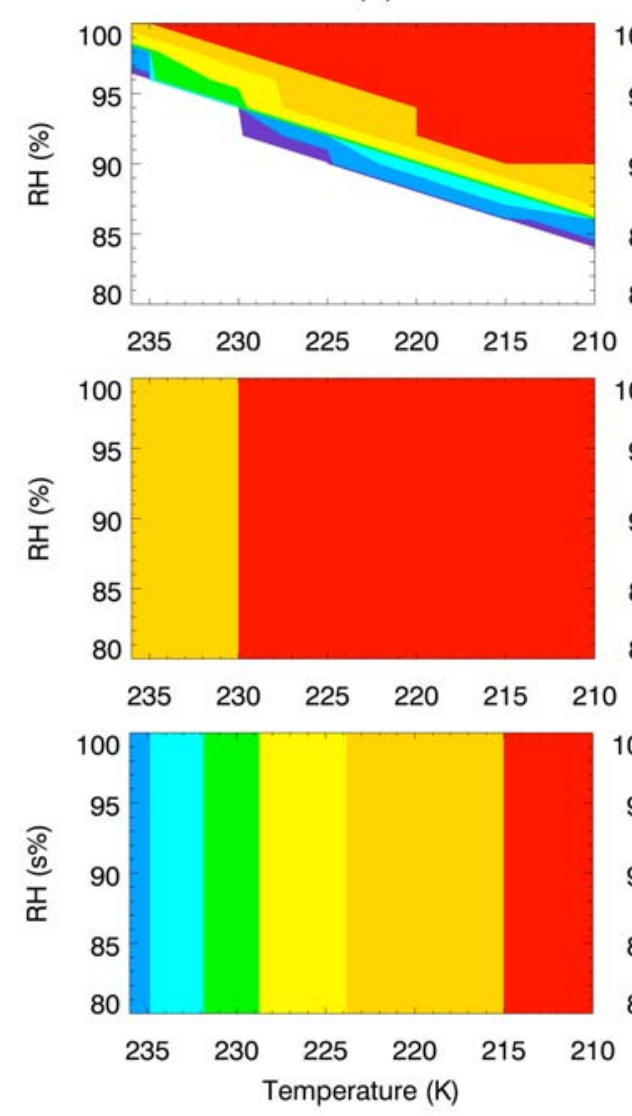

(b)
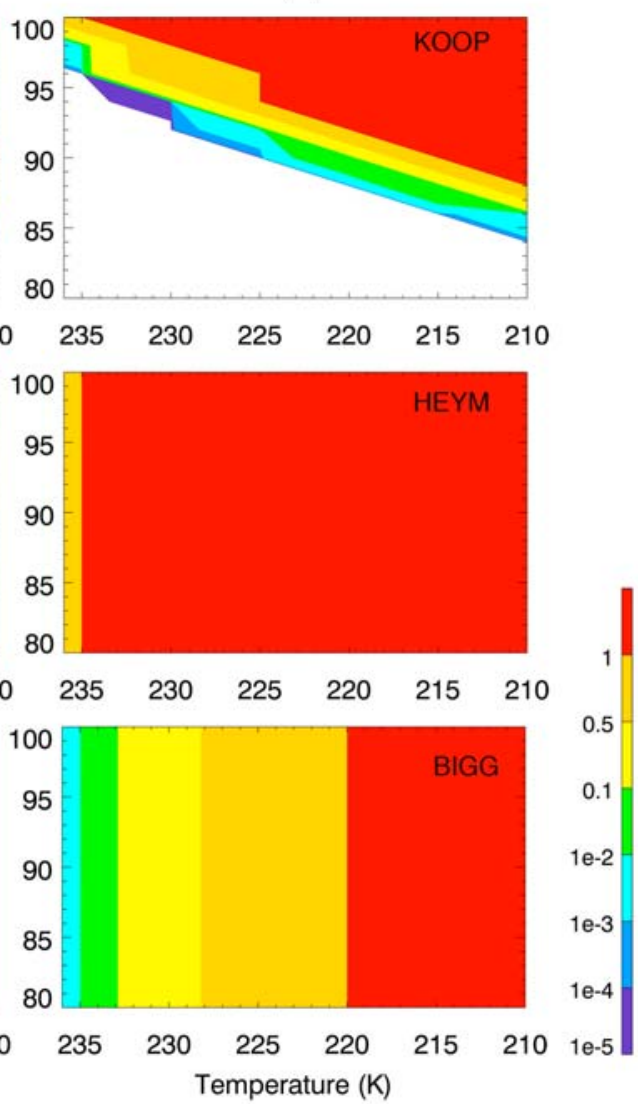

Figure 1. Freezing probability of (top) Koop et al. [2000] (KOOP), (middle) Heymsfield and Miloshevich [1993] (HEYM), and (bottom) Bigg [1953] (BIGG) as a function of $T(T<237 \mathrm{~K})$ and relative humidity with respect to water $(R H)$ for droplets with diameter of (a) $4 \mu \mathrm{m}$ and (b) $10 \mu \mathrm{m}$.

$229 \mathrm{~K}$, meaning small droplets also cannot freeze instantaneously and could evaporate completely before freezing. As stated above, both HEYM and BIGG are only temperaturedependent, whereas KOOP also depends on $R H$. Droplet freezing process could be very different under dry and humid conditions. Therefore it is necessary to test those parameterizations with the two cases of humid (FEB06) and dry (NOV16) conditions, respectively.

\subsection{Designs of Numerical Experiments}

[16] Table 1 summarizes the major simulations we conducted. Four simulations were run for different HomFPs. Three of them are referred to as HOMK, HOMH, and HOMB, with the homogeneous nucleation schemes KOOP, HEYM, and BIGG, respectively. TOPFZ was run to test the assumption that the freezing probability of all droplets is 1.0 at homogeneous nucleation levels (i.e., $T<237 \mathrm{~K}$ ). This assumption has been commonly used in many cloud models [e.g., Khain et al., 2005; Wang, 2005a, 2005b]. In these four simulations, the Meyers et al. [1992] parameterization for condensation-freezing/deposition and Vali [1975] parameterization for immersion freezing were used at $T>237 \mathrm{~K}$. To explore the impact of the immersion freezing parameterization on anvil properties, IMMB was conducted in which the BIGG scheme served as both immersion and homogenous freezing parameterizations. Therefore the only difference between HOMB and IMMB is in the type of immersion freezing parameterization used. All above simulations were run for both cases, FEB06 and NOV16. It should be noted that the homogeneous freezing parameterization is only applied to droplets in the simulation. Freezing of solution aerosols is of very low significance in deep convection [Phillips et al., 2005; Connolly et al., 2006] and is not considered in this study. In addition, droplet nucleation is only considered at

Table 1. Ice Nucleation Parameterizations Used in the Numerical Experiments for Both 6 February 2006 and 16 November 2005

\begin{tabular}{|c|c|c|c|}
\hline Simulations & Condensation-Freezing/Deposition & Immersion-Freezing & Homogeneous Freezing \\
\hline HOMK & Meyers et al. [1992] & Vali [1975] & Koop et al. [2000] \\
\hline HOMH & Meyers et al. [1992] & Vali [1975] & Heymsfield and Miloshevich [1993] \\
\hline TOPFZ & Meyers et al. [1992] & Vali $[1975]$ & freezing probability of 1.0 \\
\hline HOMB & Meyers et al. [1992] & Vali $[1975]$ & Bigg [1953] \\
\hline IMMB & Meyers et al. [1992] & Bigg [1953] & Bigg [1953] \\
\hline
\end{tabular}


(a)

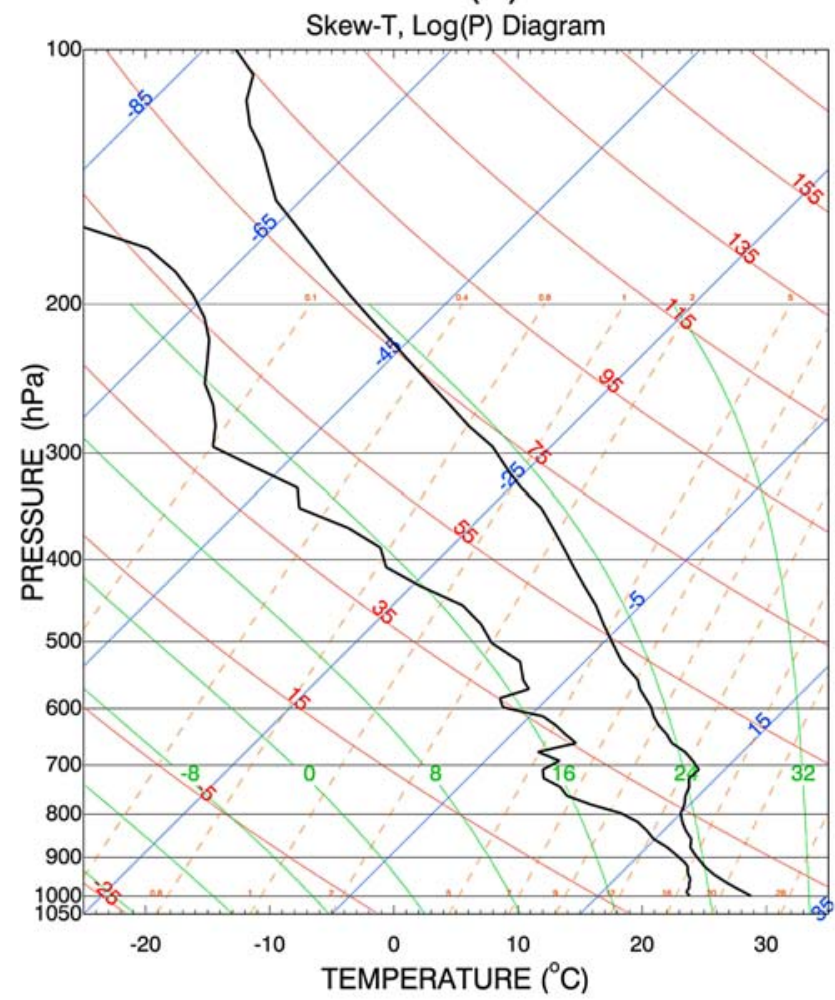

(b)

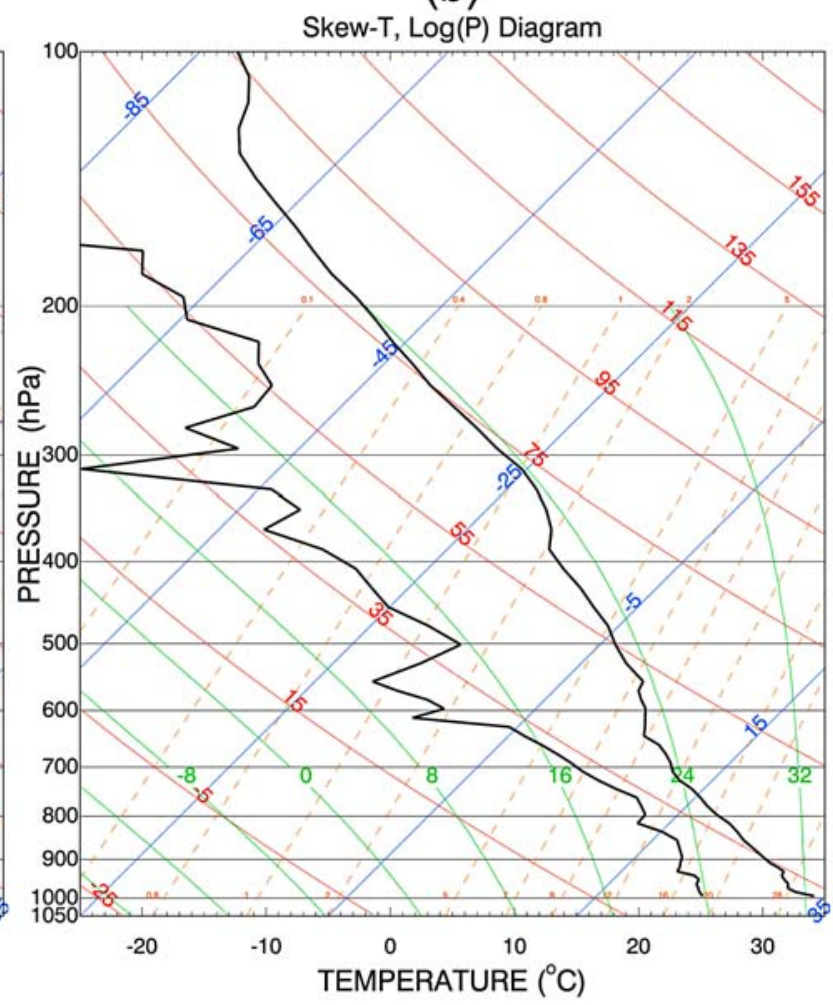

Figure 2. Skew-T figures of the initial sounding data used for (a) 6 February 2006 (FEB06) and (b) 16 November 2005 (NOV16).

temperature not less than $233 \mathrm{~K}$ since solution aerosols would freeze before being activated at very low temperatures.

[17] The initial sounding data for FEB06 and NOV16 are shown in Figure 2. It is shown that NOV16 is a much dryer case than FEB06 and has a very large middle-level dry layer. The $R H$ at $500 \mathrm{~m}$ is about $87 \%$ in the case FEB06 and $66 \%$ in NOV16. For FEB06, the radiosonde measurements from Garden Point located at the Tiwi Islands were used to drive the model. The data includes the correction of daytime dry bias [Vömel et al., 2007] and a solar zenith angle correction factor, as documented by Hume [2007]. The forcing data of water vapor, temperature and wind fields, and surface sensible and latent heat flux data were from the subdomain forcing generated for the Tiwi Islands based on the variational objective analysis of Zhang et al. [2001]. In addition, for both cases, the large-scale forcing data of temperature and water vapor above $10 \mathrm{~km}$ were not applied because (1) those data are not considered reliable [Suortti et al., 2008] and (2) we want to separate the transport of WVC by convection from the large-scale sources. For NOV16, the large-scale forcing data of water vapor, temperature, and wind fields and surface flux data were from the simulations of European Centre for Medium Range Weather Forecasts (ECMWF) available through the ARM archive (http://www.ecmwf.int/products/ data/operational_system/index.html). The nudging of the horizontal wind fields was applied using $3 \mathrm{~h}$ timescale during the simulations of the both cases.

[18] Aerosol size distributions and compositions for both FEB06 and NOV16 were obtained from the Dornier aircraft measurements. Data from the ASP, FSSP, and UHSAS were analyzed and averaged over the two flights that coincided the closest with each convection event. Ammonium sulfate and organics are the major aerosol components [Allen et al., 2008]. For the clean maritime aerosol case FEB06, the mass mixing ratio between the two aerosol components was about 1:1. However, for the polluted biomass burning aerosol case NOV16, there were more organics, constituting about $70 \%$ of the total mass [Allen et al., 2008]. Since the speciation of organic aerosols was not measured, we used the typical organic components for maritime and biomass burning aerosols from Svenningsson et al. [2006] to calculate the aerosol density and molecular weight for FEB06 and NOV16, respectively. Measured aerosol $S D s$ (Figure 3a) indicate the polluted case (NOV16) had up to 10 times higher small aerosol particle concentrations than the clean case (FEB06), but had fewer large particles. Since UHSAS data had problems during TWP-ICE, for aerosols with diameter $(D)<$ $0.27 \mu \mathrm{m}$ on FEB 06 , we obtained the values based on NOV16 but decreased by a factor calculated from the total concentration over $0.27<D<0.32 \mu \mathrm{m}$ which was measured by ASP from FEB06 divided by the similar quantity from NOV16. Thus the total number concentration in the lowest layer for FEB06 is about $210 \mathrm{~cm}^{-3}$, about 7 times lower than the polluted case NOV16. It should be noted that only data above $500 \mathrm{~m}$ were analyzed to exclude the aircraft takeoff and landing data. An exponential decrease of aerosol concentrations with height was assumed above about $3 \mathrm{~km}$ as shown in Figure 3b [Fan et al., 2007a]. The decreasing slopes of the empirical fits to the aircraft data are different for these two cases within $4 \mathrm{~km}$ near ground (Figure 3b). Following Fan 
(a)

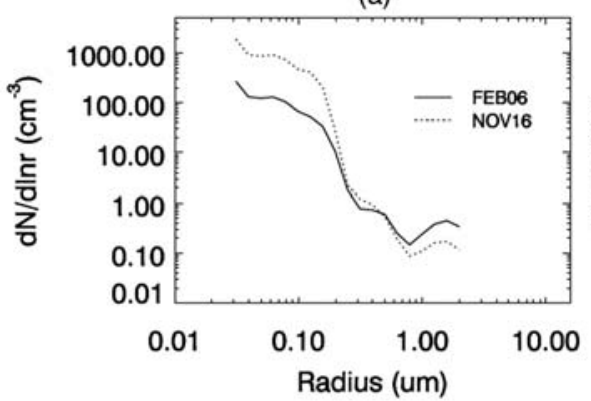

(b)

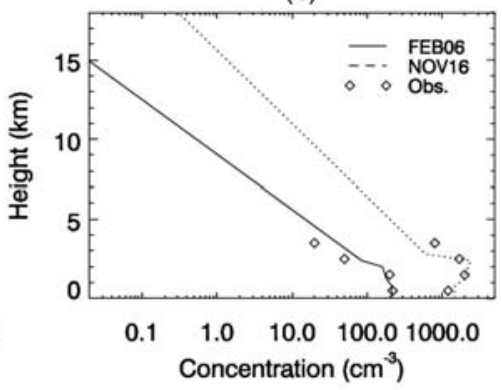

Figure 3. Aerosol (a) size distributions and (b) vertical distributions for FEB06 (solid curve) and NOV16 (dotted curve).

et al. [2007a], CCN activation was calculated using a modified Köhler theory for multiple aerosol components from Shulman et al. [1996].

[19] All simulations were run on a three-dimensional computational domain comprising $288 \times 288$ horizontal grid points with the grid spacing of $500 \mathrm{~m}$. The stretched vertical coordinate contained 73 layers with the grid spacing increasing from the bottom $(100 \mathrm{~m})$ to top $(400 \mathrm{~m})$. Periodic lateral boundary conditions were used. The dynamic time step was $2 \mathrm{~s}$. The longwave and shortwave radiation schemes from the National Center for Atmospheric Research (NCAR) Community Atmospheric Model (CAM3.0 [Kiehl et al., 1998]) were called every 3 min during the simulation. Simulations were run for $3 \mathrm{~h}$ for FEB06 and $6 \mathrm{~h}$ for NOV16, starting right before the storm. Heat bubbles were used to initialize the convection. The maximum temperature perturbation of $4^{\circ} \mathrm{C}$ was applied to the heat bubbles used in FEB06 and $2{ }^{\circ} \mathrm{C}$ for NOV16 (weaker heating temperature is needed for NOV16 because of the much larger CAPE relative to FEB06 [Connolly et al., 2008]). The bubble radii were $10 \mathrm{~km}$ in the $x$-direction, $5 \mathrm{~km}$ in the $y$-direction, and $3.0 \mathrm{~km}$ vertically (centered at the altitude of $3.0 \mathrm{~km}$ ). For NOV16, two identical adjacent heat bubbles were used in order to mimic the observed convection. The locations of the bubbles in the domain for the two cases were different and were determined based on the storm movements during the simulation time.

\section{Results}

\subsection{Case FEB06}

\subsubsection{Cloud Properties}

[20] The deep convection in the simulations starts at about $20 \mathrm{~min}$, and secondary clouds, which form from the outflow of downdrafts of the previous convection, start to form and interact with the initially formed primary clouds after about $4 \mathrm{~h}$. The C-POL radar observations also indicate that convective cells keep popping up after the primary cell. To simplify, we only analyze the model results for the primary cloud. The simulated cloud properties are compared with the aircraft, ground-based radar, and satellite measurements. Figure 4 compares the simulated and observed radar reflectivity $(Z e)$ for the cloud above $10 \mathrm{~km}$. The predicted maximum C-POL $Z e$ for clouds above $10 \mathrm{~km}$ generally agrees with the observations (Figure $4 \mathrm{a}$ ) (clouds above $10 \mathrm{~km}$ are compared since our focus is on the upper level clouds). The overprediction of $Z e$ in the beginning is probably due to the (a)

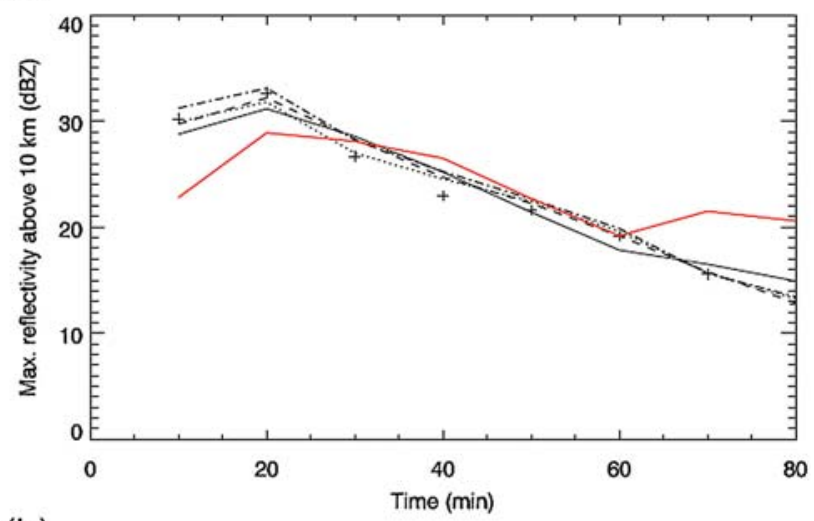

(b)

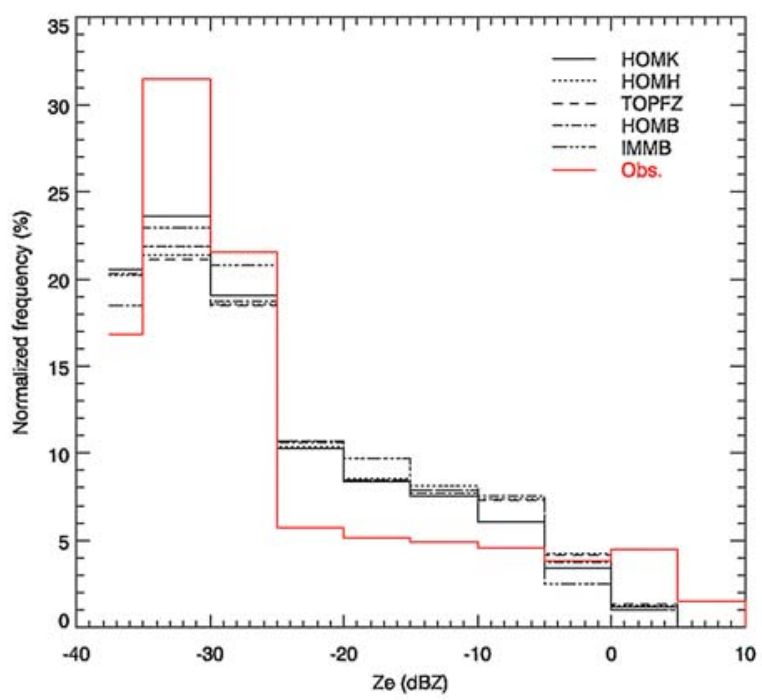

Figure 4. Radar reflectivity for cloud above $10 \mathrm{~km}$ from the simulations and observations for FEB06: (a) time series of the maximum C-POL radar reflectivity and (b) normalized frequency distribution of the airborne cloud radar (ACR) reflectivity over the $1 \mathrm{~h}$ time period (50-110 min). Only the convective cell observed over Tiwi Island is examined. 
Table 2. Cloud Properties From the Simulations for February 2006

\begin{tabular}{|c|c|c|c|c|c|c|}
\hline Quantity $^{\mathrm{a}}$ & Observations & HOMK & HOMH & TOPFZ & HOMB & IMMB \\
\hline$Q_{c}\left(\mathrm{~g} \mathrm{~m}^{-3}\right)$ & & $6.20 \mathrm{E}-02$ & $6.15 \mathrm{E}-02$ & $6.16 \mathrm{E}-02$ & $6.18 \mathrm{E}-02$ & $6.11 \mathrm{E}-02$ \\
\hline$N_{c}\left(\mathrm{~cm}^{-3}\right)$ & & 15.92 & 15.82 & 15.88 & 15.90 & 15.74 \\
\hline$Q_{r}\left(\mathrm{~g} \mathrm{~m}^{-3}\right)$ & & $1.06 \mathrm{E}-02$ & $1.08 \mathrm{E}-02$ & $1.07 \mathrm{E}-02$ & $1.07 \mathrm{E}-02$ & $9.42 \mathrm{E}-03$ \\
\hline$N_{r}\left(\mathrm{~cm}^{-3}\right)$ & & $3.93 \mathrm{E}-04$ & $3.97 \mathrm{E}-04$ & $3.98 \mathrm{E}-04$ & $3.96 \mathrm{E}-04$ & $3.76 \mathrm{E}-04$ \\
\hline$Q_{i}\left(\mathrm{~g} \mathrm{~m}^{-3}\right)$ & & $9.43 \mathrm{E}-03$ & $1.07 \mathrm{E}-02$ & $1.09 \mathrm{E}-02$ & $9.99 \mathrm{E}-03$ & $1.25 \mathrm{E}-02$ \\
\hline$N_{i}\left(\mathrm{~L}^{-1}\right)$ & & 12.70 & 13.11 & 14.15 & 12.85 & 15.21 \\
\hline$Q_{p i}\left(\mathrm{~g} \mathrm{~m}^{-3}\right)$ & & $4.11 \mathrm{E}-02$ & $4.5 \mathrm{E}-02$ & $4.48 \mathrm{E}-02$ & $4.57 \mathrm{E}-02$ & $4.46 \mathrm{E}-02$ \\
\hline$N_{p i}\left(\mathrm{~L}^{-1}\right)$ & & 0.57 & 0.58 & 0.59 & 0.58 & 1.14 \\
\hline Precipitation $(\mathrm{mm})$ & 2.57 & 2.68 & 2.69 & 2.69 & 2.67 & 2.41 \\
\hline $\operatorname{LWP}\left(\mathrm{g} \mathrm{m}^{-2}\right)$ & 1000.89 & 842.01 & 841.41 & 840.67 & 848.74 & 830.23 \\
\hline IWP $\left(\mathrm{g} \mathrm{m}^{-2}\right)$ & 900.5 & 700.50 & 709.92 & 708.75 & 704.92 & 780.05 \\
\hline Updraft velocity ${ }^{\mathrm{b}}\left(\mathrm{m} \mathrm{s}^{-1}\right)$ & & $4.04(16.7)$ & $4.07(16.9)$ & $4.06(16.8)$ & $4.05(15.6)$ & $4.28(17.6)$ \\
\hline$r_{e i}(\mu \mathrm{m})$ & & 393.88 & 360.02 & 356.50 & 366.94 & 320.56 \\
\hline Homogeneous freezing rate $\left(\mathrm{m}^{-3} \mathrm{~s}^{-1}\right)$ & & $9.1 \mathrm{E}-02$ & $8.5 \mathrm{E}-02$ & $1.21 \mathrm{E}-01$ & $5.50 \mathrm{E}-02$ & $6.48 \mathrm{E}-02$ \\
\hline Immersion freezing rate $\left(\mathrm{m}^{-3} \mathrm{~s}^{-1}\right)$ & & $5.01 \mathrm{E}-05$ & 4.82E-05 & $4.90 \mathrm{E}-05$ & $4.84-05$ & $2.0 \mathrm{E}-04$ \\
\hline Latent heat rate $\left(\mathrm{K} \mathrm{h}^{-1}\right)$ & & 0.16 & 0.22 & 0.20 & 0.17 & 0.28 \\
\hline $\mathrm{WVC}^{\mathrm{c}}\left(\mathrm{g} \mathrm{kg}^{-1}\right)$ & & $3.42 \mathrm{E}-03$ & $3.53 \mathrm{E}-03$ & $3.56 \mathrm{E}-03$ & $3.48 \mathrm{E}-03$ & $4.55 \mathrm{E}-03$ \\
\hline
\end{tabular}

\footnotetext{
${ }^{a}$ Averaged over all of the cloudy grids over $1 \mathrm{~h}$ period after the maximum updraft velocity $(50-110 \mathrm{~min})$. The threshold with total condensates of $10^{-5} \mathrm{~g}$ $\mathrm{cm}^{-3}$ is used to distinguish in-cloud and out-of-cloud grids. The observed precipitation is calculated from the C-POL radar reflectivity, and a threshold of rain rate $>0.01 \mathrm{~mm} / \mathrm{h}$ is used for both observations and simulations. The observed LWP and IWP are averaged over two available time steps with an interval of $1 \mathrm{~h}$. The immersion and homogeneous freezing rates are averaged over the domains at $7-10 \mathrm{~km}$ and $10-12 \mathrm{~km}$, respectively. The latent heat rates and $r_{e i}$ are averaged over the domains at $10-15 \mathrm{~km}$.

${ }^{b}$ Updraft velocity is averaged over all the grids with an updraft velocity of larger than $3 \mathrm{~m} \mathrm{~s}^{-1}$ over $1 \mathrm{~h}$ period (50-110 min). Values in parentheses are averaged over the domain maxima at each 10 min during 30-90 min.

${ }^{c}$ Averaged values over 14.5-17 km in Figure 10 (the differences in WVC are very small below $14.5 \mathrm{~km}$ as shown in Figure 10).
}

strong heat bubble initialization of the simulations. The higher observed radar reflectivity after $70 \mathrm{~min}$ is probably due to the interactions of the secondary clouds. The radar echo top heights with Ze of about $30 \mathrm{dBZ}$ for the convective core in the initial $30 \mathrm{~min}$ after convection starts from all the simulations are very close and about 1-2 km higher than those from the C-POL observations, also attributed to the heat bubble initialization. The modeled cloud radar $Z e$ for the anvils also reasonably agrees with the airborne radar observations except that all simulations have a lower frequency over $Z e>0$ and between -35 and $-25 \mathrm{dBZ}$ and a higher frequency at $Z e$ from -25 to $-5 \mathrm{dBZ}$ and less than $-35 \mathrm{dBZ}$ (Figure $4 \mathrm{~b}$ ) (time series of ACR is not shown because the aircraft only sampled the clouds over a short time period).

[21] The averaged cloud properties from the different simulations are shown in Table 2. The surface precipitation averaged over the precipitating grids from HOMK, HOMH, TOPFZ, and HOMB is very close (within $0.5 \%$ difference) and in good agreement with the observed value of $2.57 \mathrm{~mm}$, calculated from the C-POL radar reflectivity. The precipitation from IMMB is only $6 \%$ lower, also in good agreement with the observation. The averaged satellite-retrieved liquid water path (LWP) and ice water path (IWP) from the Minnis Cloud Products (VISST) over 2 time steps are about 15-20\% larger than model simulations. Note that the satellite measurements are available every hour for this case. The values were averaged over the columns with cloud top height larger than $10 \mathrm{~km}$ in a selected domain where the deep convection is located. Considering the large uncertainty of the satelliteretrieved data (over 50\%), the model results still fall within the observational uncertainty. These comparisons with the available observations indicate the simulated clouds generally agree with the observed cloud case.

[22] As shown in Table 2, the averaged cloud quantities for the entire cloud such as concentrations of droplet number $\left(N_{c}\right)$ and mass $\left(Q_{c}\right)$, raindrop number $\left(N_{r}\right)$ and mass $\left(Q_{r}\right)$, and ice crystal number $\left(N_{i}\right)$ and mass $\left(Q_{i}\right)$ from the simulations with different HomFPs are similar, with differences within $10 \%$ (throughout the paper, "ice mass" and "ice number" are referred to all ice particles). However, different immersionfreezing parameterizations make large differences in cloud properties. IMMB in which BIGG immersion-freezing scheme is used predicts about $25 \%$ higher $N_{i}$ and $Q_{i}$ than HOMB with the VALI immersion-freezing scheme. Although the number concentration of precipitating ice particles (snow + graupel + hail) $\left(N_{p i}\right)$ is more than 2 times larger relative to HOMB, the mass concentration $\left(Q_{p i}\right)$ even decreases a little because of smaller particle size. The substantial increase in ice particles is explained by the order of magnitude higher nucleation rate in BIGG relative to VALI (Table 2). The much larger number of small ice crystals formed through the BIGG immersion-freezing scheme in IMMB leads to more collisions and riming [Connolly et al., 2006], resulting in the above mentioned 2 times higher $N_{p i}$ (snow, graupel, and hail). However, because the much higher immersion freezing rates extensively transform droplets into ice at the middle-level layers that reduce the warm rain and the precipitating ice mass does not increase due to smaller size, the precipitation in IMMB is actually decreased by about $10 \%$. The average $Z_{e}$ during the temperature range where immersion freezing operates (i.e., $5-10 \mathrm{~km}$ ) from IMMB is actually lower by about 1-2 dBZ relative to $\mathrm{HOMB}$, because the ice particle sizes in IMMB are reduced by about $46 \mu \mathrm{m}$ on average mainly resultant from more than 2 times higher $N_{p i}$ but lower $Q_{p i}\left(Z_{e}\right.$ is proportional to size to the sixth power and only proportional to number). Considering the effect of heat bubble, the differences in $Z_{e}$ between IMMB and HOMB are not large enough to justify which one is better.

[23] The following analyses focus on anvil properties only. To exclude the convective core area, the anvil is defined as (1) cloud bases higher than $6 \mathrm{~km}$ [Frederick and Schumacher, 2008], and (2) cloud after the maximum updraft velocity has 
(a)

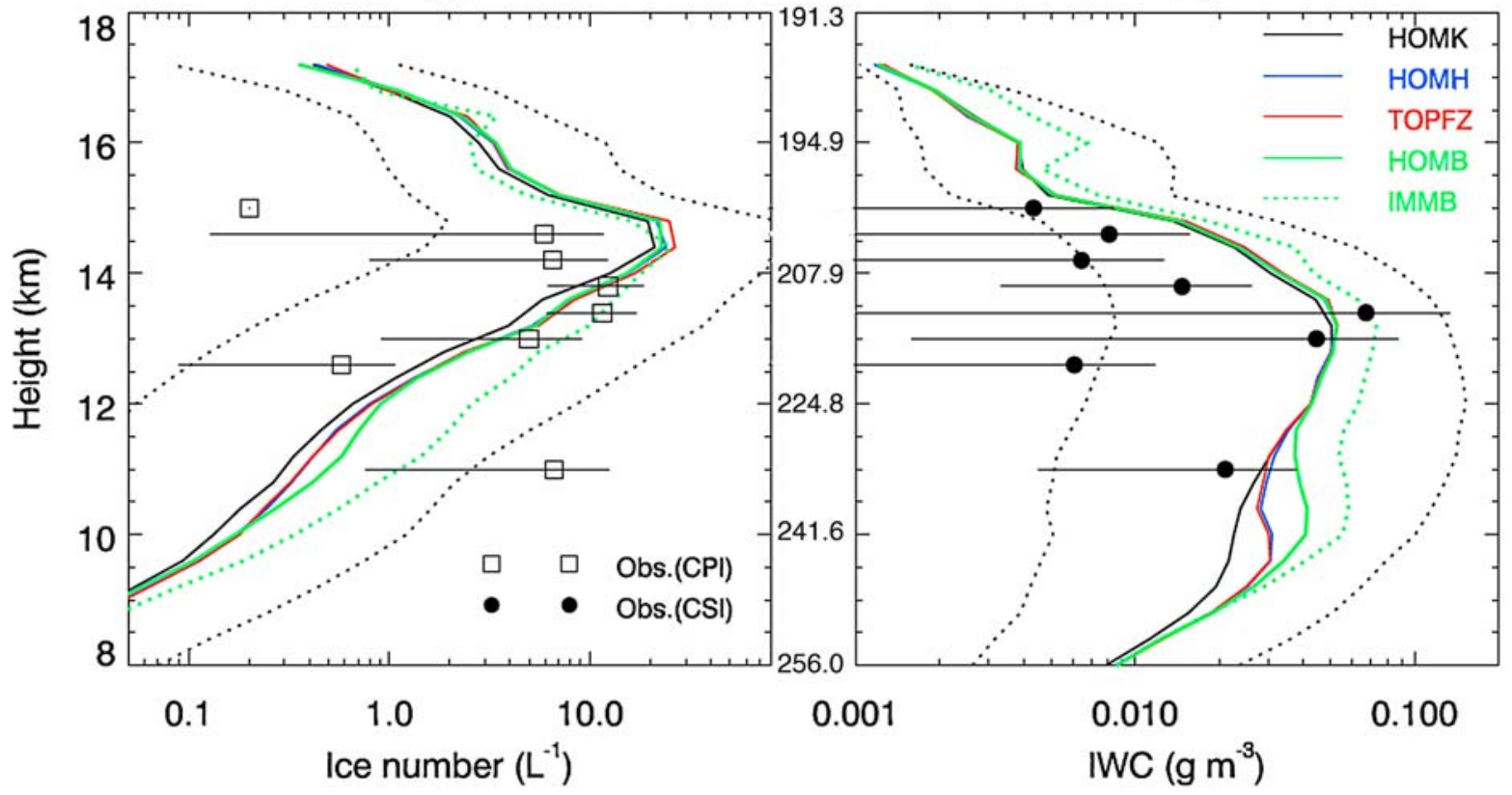

Figure 5. Vertical profiles of (a) $N_{\text {toti }}$ and (b) ice water content (IWC) in cloud anvils from the simulations and from cloud particle imager (CPI) (squares) and cloud spectrometer and impactor probe (CSI) (circles) observations for FEB06 averaged over time period of 40-100 min. $N_{\text {toti }}$ only includes ice particles with $D>$ $100 \mu \mathrm{m}$ to compare with CPI observations. IWC for the simulations is processed with the detection limit of $0.001 \mathrm{~g} \mathrm{~m}^{-3}$ for CSI. The observed data are presented as the mean values with one standard deviation uncertainty bars. The modeled $N_{\text {toti }}$ and IWC are presented as the median values. The interquatile range is shown as black dotted lines for HOMK.

been reached (i.e., at developed stage). Figure 5 provides the profiles of the microphysical properties of the cloud anvils from the simulations and the available observations. The aircraft observations on Proteus which sampled the anvil outflow (above $12 \mathrm{~km}$ ) are used here to compare with the simulated anvil clouds. The ice water content (IWC) in Figure 5 was obtained using the CSI probe, which provides bulk measures of total water content (TWC) greater than $1 \mathrm{mg}$ $\mathrm{m}^{-3}$ [Twohy et al., 2003]. The CSI TWC, which is equivalent to IWC in cirrus when no liquid is present, is accurate within approximately $15 \%$ (G. Kok, personal communication, 2007). The CSI data were only used for locations in cloud with total number concentrations greater than $10 \mathrm{~m}^{-3}$, due to the hysteresis effect whereby the TWC exponentially decayed after the Proteus exited cirrus during TWP-ICE.

[24] The measured ice number concentrations come from the CPI rather than from the more standard CIP because the CIP malfunctioned on 6 February. In the past, CPI images have been primarily used to analyze particle shapes [e.g., Um and McFarquhar, 2009] because of an uncertain sample volume, especially for particles with maximum dimensions $(D)<100 \mu \mathrm{m}$. Connolly et al. [2007] recently used a laboratory calibration to determine a scaling factor for the CPI, suggesting the CPI could accurately measure size distributions and concentrations given sufficiently large averaging times. However, their scaling factor determined for a Version 1 CPI cannot be applied to the Version 2 CPI used in TWPICE. The resulting uncertainty in the scaling factor means that there are large uncertainties in the concentrations of ice crystals, especially for $D<100 \mu \mathrm{m}$. Thus the concentrations shown from the CPI in Figure 5a only include ice particles with $D>100 \mu \mathrm{m}$. Although these concentrations have less uncertainty than those with $D<100 \mu \mathrm{m}$, there are still large differences between the CPI and CIP concentrations for $D>$ $100 \mu \mathrm{m}$, with the CIP concentrations being an average of 7.7 times greater than those of the CPI for flights on 27 and 29 January and 2 February during TWP-ICE when both the CIP and CPI were working. These uncertainties must be considered when comparing the simulations against the observations.

[25] First, the averaged ice number $\left(N_{t o t i}\right)$ for particles of $D>100 \mu \mathrm{m}$ and IWC from the observations fall in the interquartile range of the modeled values from HOMK (black dotted lines in Figures 5a and 5b). Different HomFPs predict noticeably different $N_{\text {toti }}$ and IWC between 9 and $12 \mathrm{~km}$. Compared with HOMH and TOPFZ, HOMK predicts up to $50 \%$ lower $N_{\text {toti }}$ and $30 \%$ lower IWC, corresponding to the lower homogeneous nucleation rates given in the KOOP scheme (Figure 6a). The results from HOMH are similar to those from TOPFZ, which has freezing probabilities of 1.0. This is explained by Figure 1, which shows HEYM has freezing probabilities of about 1.0 at $T<236 \mathrm{~K}$. The largest differences are from the immersion-freezing parameterizations. Compared with HOMB (the VALI scheme), IMMB (the BIGG scheme) predicts up to 2 times higher $N_{\text {toti }}$ at 9 $13 \mathrm{~km}$ relative to HOMB. Since the aircraft measurements are concentrated over $12-15 \mathrm{~km}$, have more than 1 order of magnitude variability, and are highly uncertain because of the 


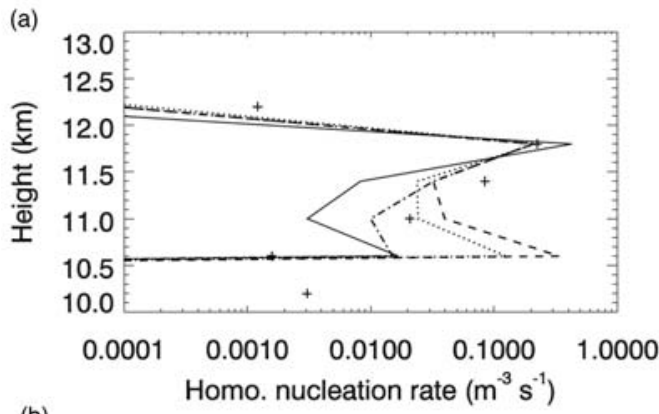

(b)

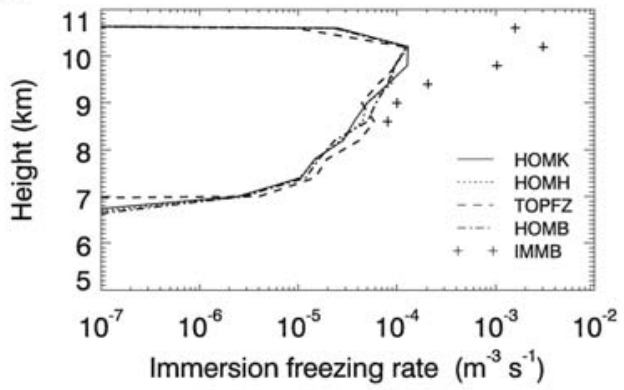

Figure 6. Profiles of (a) the homogeneous freezing rate and (b) the immersion-freezing rate averaged over the entire horizontal domain and the $1 \mathrm{~h}$ time period of 40-100 min from the simulations for FEB06.

differences between the CPI and CIP concentrations and the lack of a calibration for the DOE CPI, they are not useful to identify which simulation is most consistent with the observations.

[26] Ice particle size is especially important in terms of radiative properties of anvil clouds. The profiles of ice particle effective radius $\left(r_{e i}\right)$ for cloud anvils are presented in Figure 7a. The $r_{e i}$ is calculated based on the well-known expression for spherical particles, given by the ratio of the integration of the third and second moments of the ice particle size distribution [Wyser, 1998, equation 1]. The ice effective radii calculated from the assumed sizes for the bins of ice particles in the SBM model are much larger than the values shown in Table 2 and Figure 7a, which seems not be reasonable (the assumed sizes are not used in the microphysical calculations and do not affect any other quantities). To be consistent with the $r_{e i}$ calculation in the other modeling studies [e.g., Morrison et al., 2008], we present the results calculated from the well-known expression for spherical particles. On average, $r_{e i}$ in HOMK is about $30 \mu \mathrm{m}$ larger than those in HOMH and TOPFZ, and about $70 \mu \mathrm{m}$ larger than that in HOMB (Table 2). Note the averages of $r_{e i}$ are obtained by averaging over the grids with total ice particle concentrations larger than $10^{-6} \mathrm{~L}^{-1}$. These trends correspond to the increase in ice number shown in Figure 5. The BIGG immersionfreezing (IMMB) results in the largest difference: $r_{e i}$ is reduced by up to $100 \mu \mathrm{m}$ at $10-14 \mathrm{~km}$ (Figure 7a). Compared with HOMB where the VALI immersion-freezing scheme is used, the average $r_{e i}$ over $10-15 \mathrm{~km}$ in IMMB is about $46 \mu \mathrm{m}$ smaller (Table 2). To examine the radiative influences of those different sizes of ice particles, we calculate the extinction coefficients at the visible wavelength based on the ice effective radius and IWC using the formula developed by $\mathrm{Fu}$ [1996]. Note that the ice effective radius used here is calculated based on IWC and total projected area of all particles (the projected area of ice particles is obtained by assuming the spherical shape), to be consistent with that used by $F u$ [1996]. Neither of the ice effective radius calculations is used in the radiation scheme in which the ice effective radius is an assumed and fixed value. This should be improved in the future versions of the model. HOMK has the smallest extinction coefficients and IMMB has the largest values below $12 \mathrm{~km}$ (Figure 7b), corresponding to the largest and smallest ice particle size, respectively. The extinction (a)

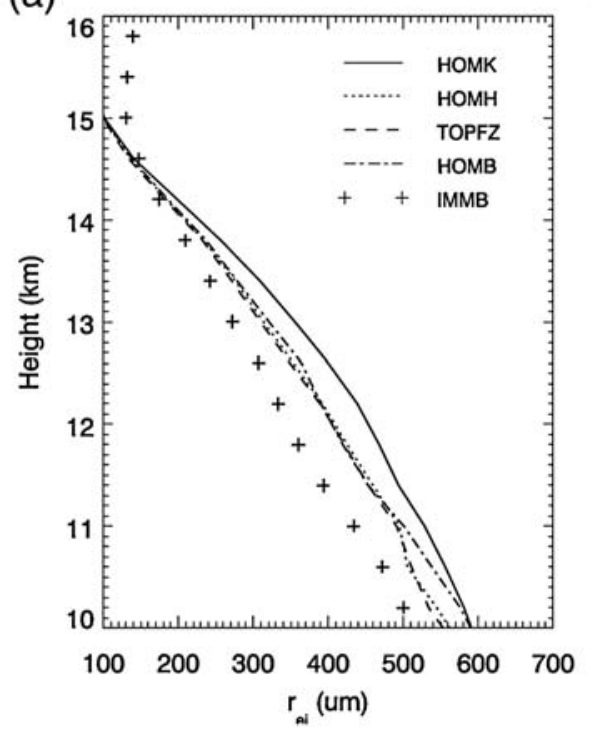

(b)

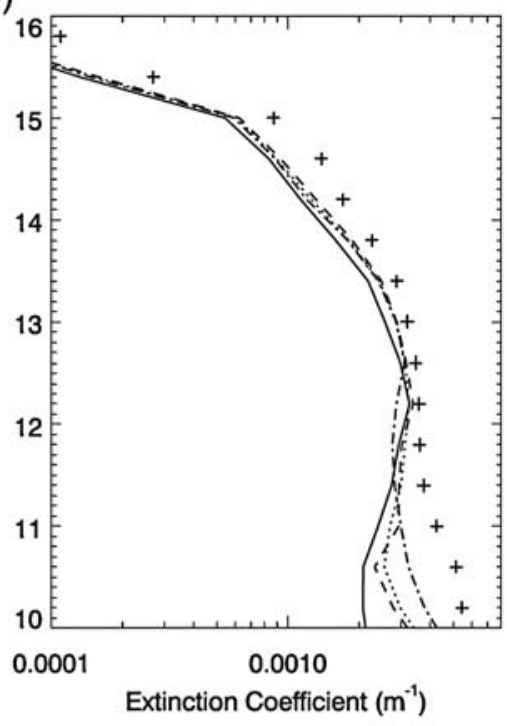

Figure 7. Profiles of (a) ice particle effective radius and (b) extinction coefficient averaged over the cloud grids and time period of $60-80 \mathrm{~min}$ from the simulations. 


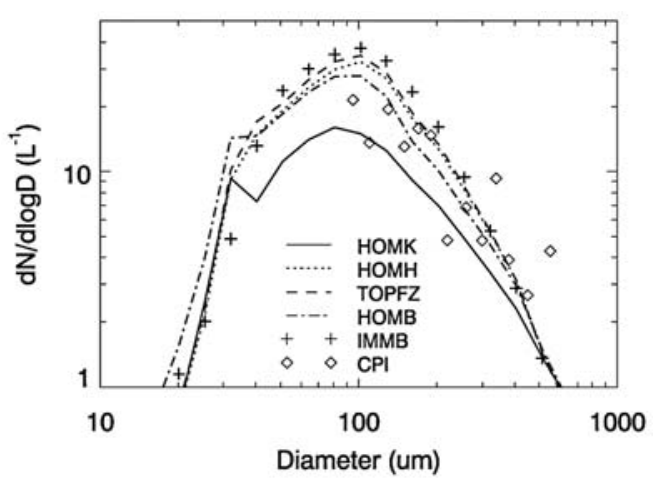

Figure 8. Particle size distribution averaged over the cloud anvil between 12 and $15 \mathrm{~km}$ where most of the observations were made and over time period of 60-80 min from the simulations and CPI observations (diamonds) for FEB06.

coefficients in HOMK is about $40 \%$ lower than those in HEYM and TOPFZ, and about $70 \%$ lower than those in HOMB. The extinction coefficients in IMMB are up to 2 times larger compared with those in HOMK, and up to $50 \%$ larger than HOMB (the VALI scheme). Therefore the cloud albedo and radiative forcing of the anvils is much affected by different homogeneous and heterogeneous freezing parameterizations.

[27] The averaged simulated ice particle SDs for cloud anvils shown in Figure 8 are compared with CPI measurements for $D>100 \mu \mathrm{m}$. Except HOMK, other simulations tend to over-predict ice particles with $D$ between 100 and $200 \mu \mathrm{m}$ and predict reasonably good ice number for $D$ between 200 and $500 \mu \mathrm{m}$. Since the CPI concentrations for $D<200 \mu \mathrm{m}$ may be biased low, the overprediction of the small crystals by the simulations must be interpreted with some caution. The simulation with KOOP predicts about $50 \%$ fewer ice particles compared with the simulations with other HomFPs and is in poorer agreement with the presented observations. Again, because of the larger variability of the observations relative to the differences among simulations and shattering problem related to the probes, we want to be cautious in judging a better simulation here.

\subsubsection{Anvil Updraft Velocity}

[28] The updraft velocity averaged over all clouds does not show significant differences among the simulations with different HomFPs, as shown in Table 2. Note that changes less than $10 \%$ are too small and considered as insignificant for the results presented in this paper. The latent heat release from droplet freezing and deposition processes should increase air buoyancy and enhance convection [Khain et al., 2005]. Therefore updraft velocity in cloud anvils with different HomFPs could have larger differences. Figure 9a shows the averaged updraft velocities for cloud anvils. Below $14.5 \mathrm{~km}$, HOMK has the lowest averaged updraft velocities and IMMB has the highest, with the difference up to $20 \%$. The differences in anvil updraft velocity among the simulations with different HomFPs are less than $10 \%$. The relatively lower homogeneous freezing rates in HOMK result in less latent heat release (Table 2). However, in IMMB, the order of magnitude higher immersion-freezing rates (Table 2) release much higher latent heat relative to the other simulations and enhance the convection. The homogeneous freezing rates in the anvil increase on average by over $15 \%$ relative to those in HOMB (Figure $6 \mathrm{~b}$ and Table 2 ), because stronger convection transports more droplets to the upper levels. Eventually, the latent heat release averaged over the domain over $10-15 \mathrm{~km}$ from the freezing and deposition processes increases by $60 \%$ from HOMB to IMMB (Table 2), explaining why convection in the cloud anvil is much stronger in IMMB than that in HOMB. Again, results from HEYM and TOPFZ are very similar.

\subsubsection{Anvil Size}

[29] As stated in section 1, the anvil size and lifetime are very important parameters that determine the radiative forcing of deep convective systems. Because of the interactions with the secondary clouds after about $4 \mathrm{~h}$ of simulation time, the final dissipation of cloud anvils cannot be examined in this case. Figure $9 \mathrm{~b}$ shows the evolution of the anvil size from all simulations. Anvil size is calculated by the total columns with total water path greater than $25 \mathrm{~g} \mathrm{~m}^{-2}$ multiplied by the area of a column (square of the horizontal grid spacing). Except HOMK, the simulations from the other HomFPs predict very similar anvil sizes. The smaller anvil size around $90 \mathrm{~min}$ in HOMK is primarily due to the relatively weaker convection. After $2 \mathrm{~h}, \mathrm{HOMK}$ predicts up to $25 \%$ larger anvil size than those from the other HomFPs. By examining the 3-D pictures of the cloud anvil, we found that the shrinkage of the anvil is much slower at $10-13 \mathrm{~km}$ probably because of the larger ice particle size in HOMK. For IMMB, the convection for the entire cloud is stronger due to the larger latent heat release resulted from the larger immersion-freezing rates, which leads to the larger spread of the cloud anvil. Therefore IMMB predicts the largest anvil size, with an increase of over $30 \%$ on average compared with HOMB.

\subsubsection{Water Vapor Content in the TTL}

[30] Deep convection can transport water vapor from the lower troposphere directly to the TTL and moisten the air in the TTL [e.g., Smith et al., 2006]. Figure 10 shows the moistening effect of deep convection on the air of the TTL (i.e., clear-sky WVC) from all the simulations. The red curve is the profile of WVC right before convection starts, and the other profiles from the simulations are averaged over the outof-cloud grids in $1 \mathrm{~h}$ time periods (40-100 min) after active convection starts. The moistening effect of the deep convection is seen above $15 \mathrm{~km}$ (Figure 10), and increases WVC by about a factor of 2-3 on average compared with the WVC of $1.56 \times 10^{-3} \mathrm{~g} \mathrm{~kg}^{-1}$ before convection (Table 2). Considering the dehydration via cloud formation in the TTL, this could represent the minimum amount of water vapor transport by deep convection. Note that values presented here are only averaged over a $1 \mathrm{~h}$ period mostly at the mature convection stage. The longer the time after the active convection, the less moistening effect could be seen because dehydration processes such as cirrus formation and chemical reactions would deplete water vapor [Fueglistaler et al., 2009]. As expected, the WVC of clear sky in the TTL from different HomFPs has no significant difference because both convection and anvil size are similar among those simulations. The BIGG immersion freezing (IMMB) makes the largest differences and predicts about $30 \%$ higher $\mathrm{WVC}$ relative to HOMB. The much higher WVC in IMMB results from stronger transport due to stronger convection and larger anvil size (i.e., more cloudy grids) as shown in Figure 9b. 


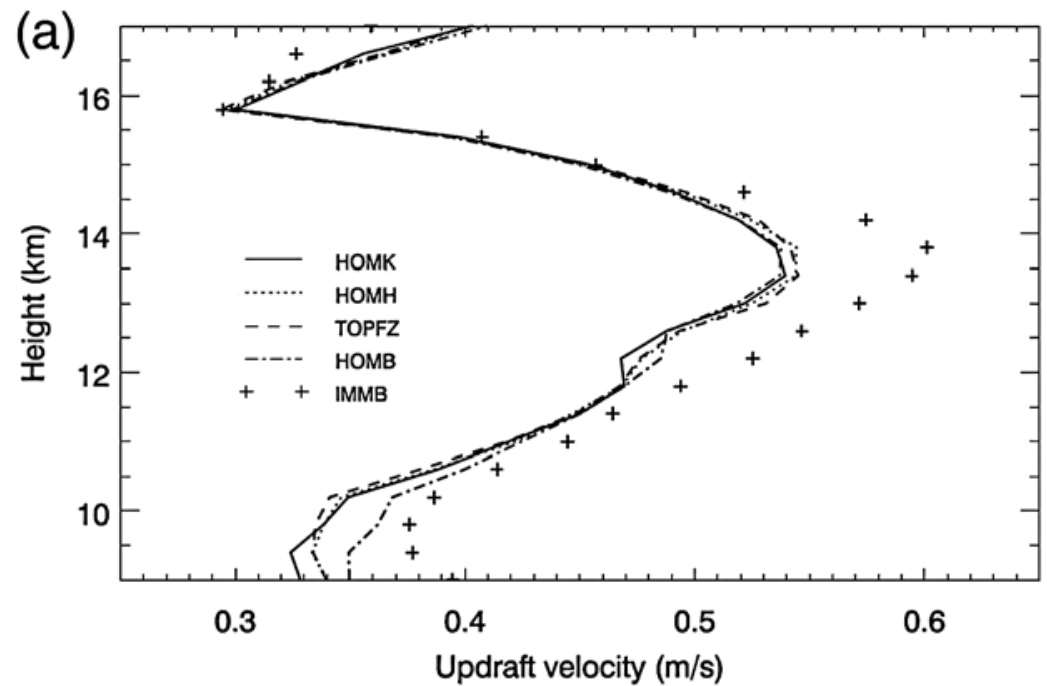

(b)

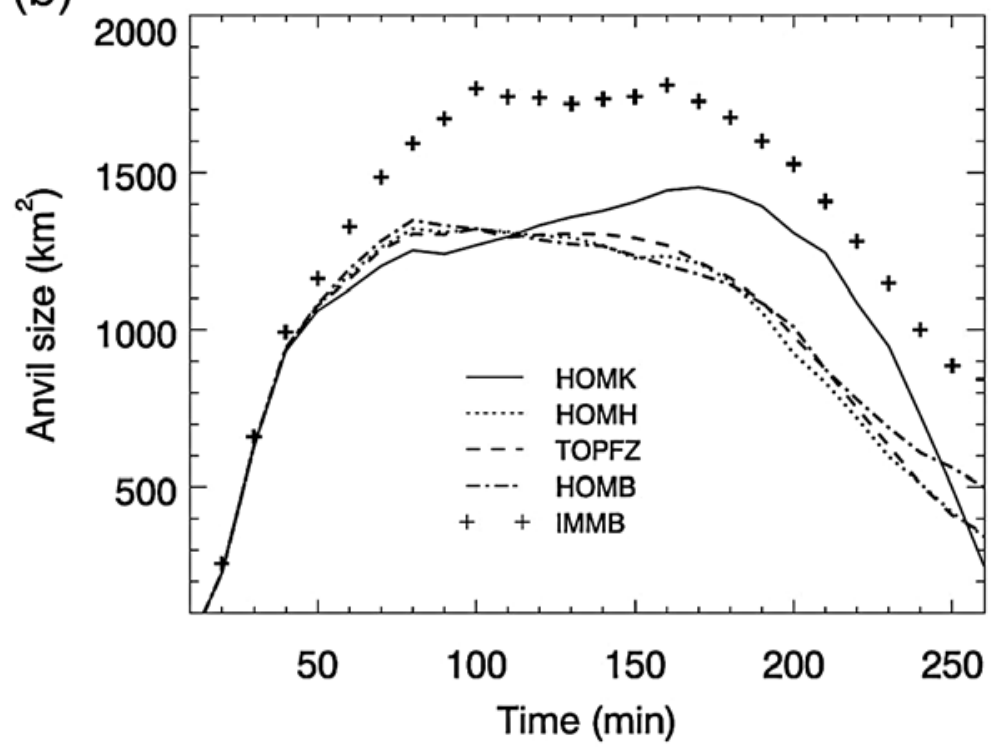

Figure 9. Profiles of (a) updraft velocity in cloud anvils averaged over the cloud grids and the $1 \mathrm{~h}$ time period (40-100 $\mathrm{min}$ ), and (b) time series of the anvil size from the simulations for FEB06. Anvil size is calculated by the total columns with total water path greater than $10 \mathrm{~g} \mathrm{~m}^{-2}$ multiplied by the area of a column (square of the horizontal grid spacing).

[31] In summary, for the clean and humid case, the different HomFPs have little impact on the entire convection, precipitation, and anvil size, but some anvil properties such as ice particle number and mass, effective radius, and extinction coefficient are much changed. The BIGG immersion-freezing parameterization gives much higher droplet freezing rates, leading to stronger deep convection, a larger anvil, more ice number, reduced ice particle size, and less precipitation.

\subsection{Case NOV16}

\subsubsection{Cloud Properties}

[32] Contrasting with the previous clean and humid case, NOV16 is a polluted and dry case. The deep convection also starts at about $30 \mathrm{~min}$ also because of the triggering by the warm bubbles. The lifetime of the entire DCC has been simulated for this case because no secondary clouds interact with the primary clouds. The anvil base is also at about 10.2 $10.6 \mathrm{~km}$. The overall cloud properties are summarized in Table 3. The simulated clouds are also compared with C-POL radar retrievals, satellite measurements, and aircraft measurements. The time dependence of the maximum $Z_{e}$ above $10 \mathrm{~km}$ from the simulations has a similar pattern with the observations but is over-predicted by all the simulations in the initial $30 \mathrm{~min}$ (Figure 11a). The over-prediction is associated with the strong bubble initialization. The observed radar echo top for $Z_{e}$ of about $30 \mathrm{dBZ}$ shown in Figure $11 \mathrm{~b}$ is also in good agreement with those from the simulations testing different HomFPs except in the initial $30 \mathrm{~min}$. The surface precipitation averaged over the precipitating grids from HOMK, HOMH, TOPFZ, and HOMB is about $0.31-$ 


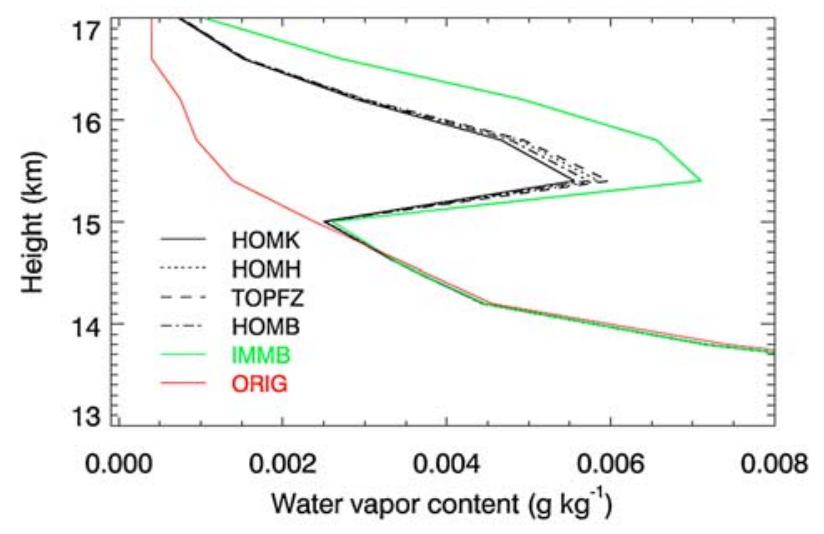

Figure 10. Profiles of water vapor content averaged over the out-of-cloud grids (with total cloud condensates $<10^{-5} \mathrm{~g} \mathrm{~kg}^{-1}$ ) during the $1 \mathrm{~h}$ time period $(40-100 \mathrm{~min}$ ) from the simulations for FEB06.

$0.34 \mathrm{~mm}$, over $20 \%$ higher than the observed value of $0.24 \mathrm{~mm}$ as shown in Table 3 , while the precipitation in IMMB is very close to the observed value. The satellite-observed LWP and IWP are only available at one time for this case, which is at the time of active convection. Compared with the observed IWP, IMMB gives about 15\% higher IWP and HOMB predicts about $15 \%$ lower IWP. Since the retrieved precipitation and IWP have large uncertainties and no simulation consistently agrees with both quantities, it is difficult to fully justify a better simulation.

[33] The ice crystal and precipitating ice number concentrations averaged over the entire cloud in the simulations with different HomFPs differ by more than they did for the FEB06 case, although the cloud droplet concentrations are still very similar (Table 3 ). The $N_{i}$ is over $20 \%$ and $N_{p i}$ is over
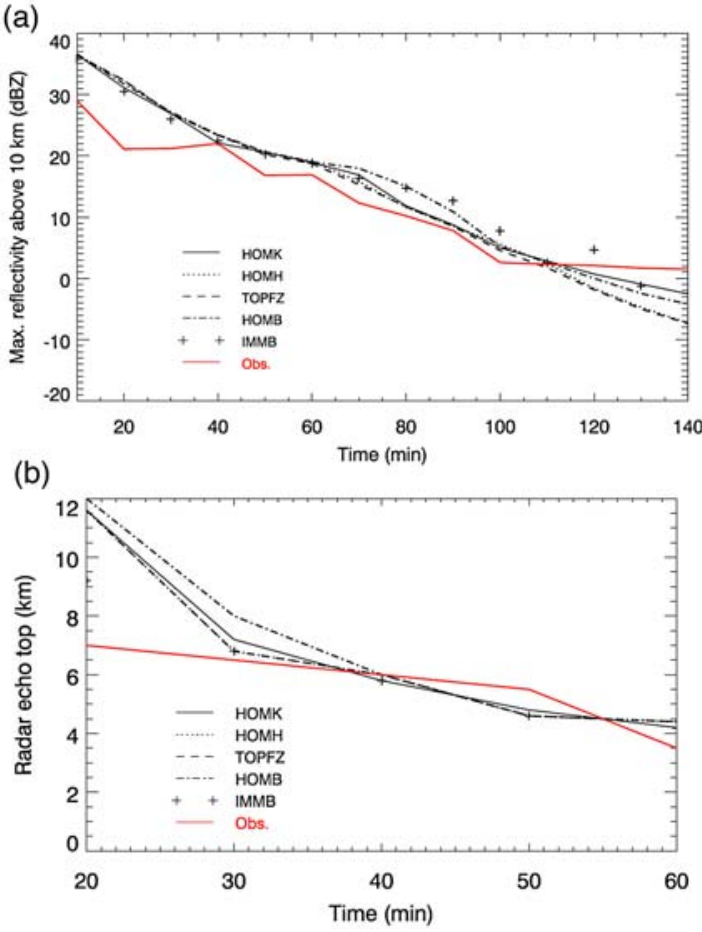

Figure 11. Comparison of simulations against observed C-POL radar data: (a) time series of the maximum C-POL radar reflectivity for cloud above $10 \mathrm{~km}$ for NOV16, and (b) time series of radar echo top with $Z_{e}$ of about $30 \mathrm{dBZ}$. Radar echo tops are defined as the highest altitudes for a certain value of radar reflectivity (here for $30 \mathrm{dBZ}$ ).

Table 3. Cloud Properties From the Simulations for 16 November 2005

\begin{tabular}{|c|c|c|c|c|c|c|}
\hline Quantity $^{\mathrm{a}}$ & Observations & HOMK & HOMH & TOPFZ & HOMB & IMMB \\
\hline$Q_{c}\left(\mathrm{~g} \mathrm{~m}^{-3}\right)$ & & 3.94E-03 & $3.92 \mathrm{E}-03$ & $3.90 \mathrm{E}-03$ & $3.94 \mathrm{E}-03$ & $3.88 \mathrm{E}-03$ \\
\hline$N_{c}\left(\mathrm{~cm}^{-3}\right)$ & & 3.75 & 3.72 & 3.73 & 3.74 & 3.71 \\
\hline$Q_{r}\left(\mathrm{~g} \mathrm{~m}^{-3}\right)$ & & $2.67 \mathrm{E}-02$ & $2.64 \mathrm{E}-02$ & $2.63 \mathrm{E}-02$ & $2.67 \mathrm{E}-02$ & $2.25 \mathrm{E}-02$ \\
\hline$N_{r}\left(\mathrm{~cm}^{-3}\right)$ & & $1.26 \mathrm{E}-04$ & $1.26 \mathrm{E}-04$ & $1.25 \mathrm{E}-04$ & $1.26 \mathrm{E}-04$ & $1.32 \mathrm{E}-04$ \\
\hline$Q_{i}\left(\mathrm{~g} \mathrm{~m}^{-3}\right)$ & & $1.15 \mathrm{E}-02$ & $1.37 \mathrm{E}-02$ & $1.40 \mathrm{E}-02$ & $1.18 \mathrm{E}-02$ & $1.31 \mathrm{E}-02$ \\
\hline$N_{i}\left(\mathrm{~L}^{-1}\right)$ & & 234.76 & 314.58 & 351.80 & 206.69 & 146.89 \\
\hline$Q_{p i}\left(\mathrm{~g} \mathrm{~m}^{-3}\right)$ & & $4.28 \mathrm{E}-02$ & $4.20 \mathrm{E}-02$ & $4.22 \mathrm{E}-02$ & $4.31 \mathrm{E}-02$ & 4.15E-02 \\
\hline$N_{p i}\left(\mathrm{~L}^{-1}\right)$ & & 0.51 & 0.60 & 0.62 & 0.49 & 1.02 \\
\hline Precipitation $(\mathrm{mm})$ & 0.24 & 0.34 & 0.32 & 0.31 & 0.34 & 0.28 \\
\hline $\operatorname{LWP}\left(\mathrm{g} \mathrm{m}^{-2}\right)$ & 1878 & 1493.8 & 1488.8 & 1488.3 & 1451.4 & 1519.6 \\
\hline IWP $\left(\mathrm{g} \mathrm{m}^{-2}\right)$ & 1929 & 2057.1 & 2107.4 & 2113.5 & 1605.3 & 2488.5 \\
\hline Updraft velocity $^{\mathrm{b}}\left(\mathrm{m} \mathrm{s}^{-1}\right)$ & & $6.64(18.7)$ & $6.66(19.2)$ & $6.66(19.8)$ & $6.67(19.1)$ & $6.78(20.1)$ \\
\hline$r_{e i}(\mu \mathrm{m})$ & & 290.10 & 252.06 & 267.41 & 264.34 & 232.45 \\
\hline Anvil lifetime (min) & & 350 & 370 & 370 & 320 & 370 \\
\hline Homogeneous freezing rate $\left(\mathrm{m}^{-3} \mathrm{~s}^{-1}\right)$ & & 2.86 & 5.68 & 6.42 & 2.22 & 4.48 \\
\hline Immersion freezing rate $\left(\mathrm{m}^{-3} \mathrm{~s}^{-1}\right)$ & & $1.19 \mathrm{E}-02$ & $1.16 \mathrm{E}-02$ & $1.15 \mathrm{E}-02$ & $1.19 \mathrm{E}-02$ & 0.19 \\
\hline Latent heat rate $\left(\mathrm{K} \mathrm{h}^{-1}\right)$ & & 0.59 & 1.20 & 1.37 & 0.69 & 0.49 \\
\hline Water vapor ${ }^{\mathrm{c}}\left(\mathrm{g} \mathrm{kg}^{-1}\right)$ & & $3.11 \mathrm{E}-03$ & $3.69 \mathrm{E}-03$ & $3.73 \mathrm{E}-03$ & $3.18 \mathrm{E}-03$ & $3.63 \mathrm{E}-03$ \\
\hline
\end{tabular}

${ }^{a}$ Averaged over all of the cloudy grids over 1-h period after the maximum updraft velocity ( $\left.40-100 \mathrm{~min}\right)$. The same threshold is used for in-cloud grids as in Table 2. The observed LWP and IWP are the averaged values at only one timestep, which is at the active convection. The immersion and homogeneous freezing rates are averaged over the domains at $7-10 \mathrm{~km}$ and $10-12 \mathrm{~km}$, respectively. The latent heat rates and $r_{e i}$ are averaged over the domains at $10-15 \mathrm{~km}$.

${ }^{b}$ Updraft velocity is averaged over all the grids with an updraft velocity of larger than $3 \mathrm{~m} \mathrm{~s}^{-1}$ over $1 \mathrm{~h}$ period $(40-100 \mathrm{~min})$. Values in the parentheses are averaged over the domain maxima at each 10 min during 30-90 min.

${ }^{\mathrm{c}}$ Averaged values over 14.5-17 km in Figure 15 (the differences in WVC are very small below $14.5 \mathrm{~km}$ as shown in Figure 15). 
(a)

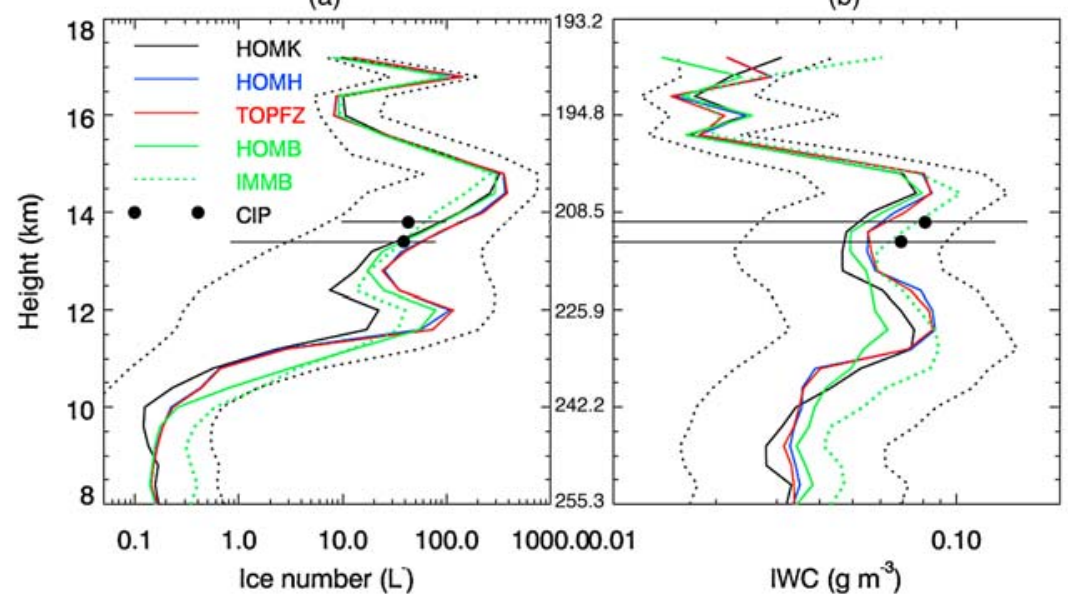

Figure 12. As in Figure 5, but for NOV16 over the $1 \mathrm{~h}$ period (40-100 min) to compare with the CIP measurements.

$15 \%$ higher in HOMH and TOPFZ compared with those in HOMK. Although $N_{p i}$ increases by over $100 \%$ from HOMB to IMMB, $Q_{p i}$ decreases because smaller sizes of precipitating ice particles (deposition growth is not efficient for smaller ice particles and under dry condition). The lower ice particle number concentrations in HOMK are explained by $50 \%$ lower homogeneous freezing rates (Table 3) due to the low freezing probabilities at low $R H$ shown in Figure 1. Since the freezing probabilities determined by KOOP highly depend on $R H$, differences between the simulation with KOOP and those with other HomFPs are expected to be greater in this dry case than the previous humid case (FEB06). Similar to FEB06, the BIGG immersion-freezing scheme (IMMB) leads to a stronger convective cloud. Compared with the VALI parameterization (HOMB), the order of magnitude higher immersion-freezing rates given by BIGG result in over 2 times higher precipitating ice particle number and stronger convection (Table 3 ). Similar to the clean-humid case FEB06, the precipitation is also decreased by the higher immersion-freezing rate in this polluted-dry case. The decrease is $18 \%$ compared with HOMB, more significantly relative to the previous case due to the dry condition at the middle levels in this case.

[34] Figure 12 provides the profiles of anvil microphysical properties from the simulations and the available aircraft measurements. The $N_{\text {toti }}$ with the $R H$-dependent HomFP (HOMK) are up to $70 \%$ lower than those with the temperaturedependent HomFPs (HOMH, HOMB, and TOPFZ) (Figure 12a). The much lower $N_{\text {toti }}$ in HOMK results from the low freezing probabilities given by KOOP because of low $R H$ and/or small droplet size in this polluted-dry case. The KOOP scheme makes larger differences around $12 \mathrm{~km}$ where the observations are absent. In addition, CIP measurements could overpredict $N_{\text {toti }}$ because of some artificial factors such as shattering [McFarquhar et al., 2007]. All simulations seem to under-predict IWC (Figure 12b), but the very large variability of the measurements and the large uncertainty associated with the retrieved IWC make it less conclusive. Nevertheless, the simulation with the BIGG immersion freezing gives up to 2.5 times higher ice particle number and mass concentrations below $11 \mathrm{~km}$ compared with the simulations with the VALI scheme (HOMB).
[35] The ice particle effective radius is also sensitive to the different HomFPs in this dry case. Because of much less ice nucleated in HOMK, the $r_{e i}$ is up to $50 \mu \mathrm{m}$ larger than those in HOMH and TOPFZ (Figure 13a). On average, it is about $30 \mu \mathrm{m}$ larger (Table 3). IMMB has the smallest $r_{e i}$ and the averaged $r_{e i}$ is over 30 and $50 \mu \mathrm{m}$ smaller relative to HOMB and HOMK, respectively, due to the largest immersion freezing rate and the enhanced homogeneous nucleation rate as shown in Table 3. Extinction coefficients are also calculated as in FEB06, but large differences are found in this case. Relative to HOMH, TOPFZ, and HOMB, the extinction coefficient in HOMK is about $30 \%$ smaller on average. The BIGG immersion freezing scheme (IMMB) predicts the largest extinction coefficients due to smallest ice particle sizes and the largest ice water content (Figure 13b). The extinction coefficients in IMMB are doubled on average compared with those in HOMK, and about $60 \%$ larger than HOMB (the VALI scheme) below $13 \mathrm{~km}$. Therefore the cloud albedo and radiative forcing of the anvils is also very sensitive to different homogeneous and heterogeneous freezing parameterizations in this case.

\subsubsection{Anvil Updraft Velocity}

[36] Although the BIGG immersion freezing parameterization enhances the homogeneous freezing rates by $100 \%$ on average (from HOMB to IMMB) (Table 3), the latent heat is about $30 \%$ lower relative to HOMB because the latent heat is more sensitive to the deposition growth and the deposition growth is inefficient due to the smaller ice particles and the dry condition as mentioned two paragraphs before. As a result, updraft velocity in the cloud anvil is close to HOMK and about 20\% lower than HOMB around 13-15 km. HOMK gives about $20 \%$ lower updraft velocity around $13-15 \mathrm{~km}$ relative to HEYM and TOPFZ (not shown). Those changes correspond to the changes in latent heat release from freezing and deposition processes as shown in Table 3 . The latent heat release averaged over the domain in HOMK and HOMB is only about $50 \%$ of those in HOMH and TOPFZ.

\subsubsection{Anvil Size and Lifetime}

[37] Figure 14 shows the size and evolution of anvils from the simulations. HOMH and TOPFZ have very similar anvil size and lifetime with differences $<5 \%$. As in FEB06, 
(a)

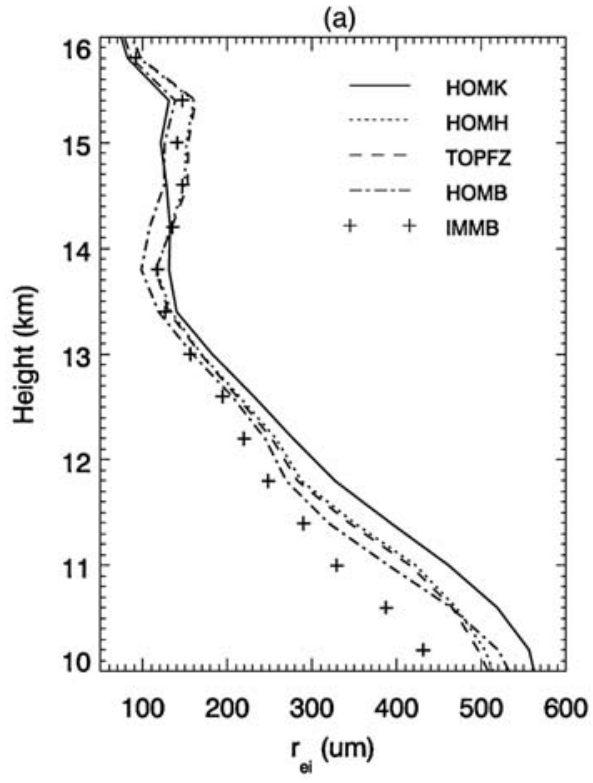

(b)

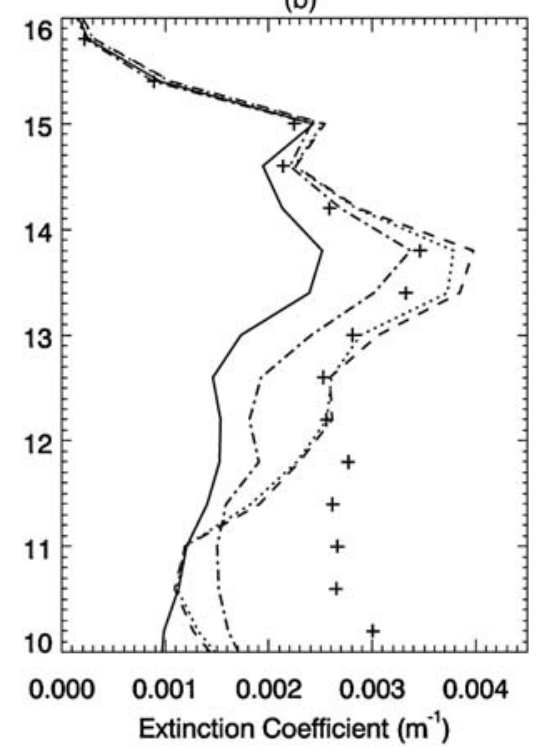

Figure 13. Profiles of (a) ice particle effective radius and (b) extinction coefficient averaged over the cloud grids and time period of $60-80$ min from the simulations.

the smaller anvil size in HOMK in the beginning is due to relatively weaker convection compared with HOMH and TOPFZ, and the cloud anvil in HOMK dissipates more slowly because ice particles are larger and evaporate more slowly. Faster evaporation for smaller ice particles in the anvils in HOMH, TOPFZ, and HOMB results in faster shrinkage of cloud anvils. Note that the effect of ice crystal sedimentation would be negligible because ice crystal sizes in the anvils are small so that they have very small fall velocity. After $4 \mathrm{~h}$, HOMK predicts up to $20 \%$ larger anvil size than HOMH and TOPFZ, although the anvil lifetime is still about $20 \mathrm{~min}$ shorter. The anvil size in HOMB dissipates the fastest, related to smaller ice particle size and lower IWC at $11-13 \mathrm{~km}$. Its anvil lifetime is about 20 min shorter relative to HOMK and 40 min shorter relative to HOMH and TOPFZ. Certainly, the simulation with the BIGG immersion-freezing parameterization (IMMB) makes the largest anvil size in the initial $4 \mathrm{~h}$ induced by the stronger convection. However, the cloud anvil shrinks faster compared with HOMH and TOPFZ,

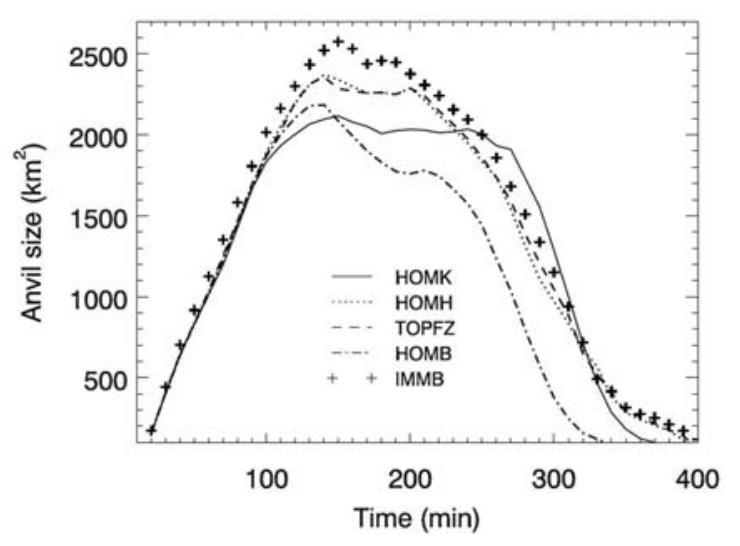

Figure 14. As in Figure 9b, but for NOV16. which is associated with smaller ice particle size and relatively weaker updraft velocity in the cloud anvils, and end up with similar anvil lifetime with HOMH and TOPFZ. Compared with HOMB, the anvil size is up to 2.5 times larger about $2 \mathrm{~h}$ later and the lifetime is about $40 \mathrm{~min}$ longer.

\subsubsection{Water Vapor Content in the TTL}

[38] The moistening effect on the TTL clear air by deep convection is also very significant in this polluted-dry case, because of stronger convection and larger cloudy-area in the domain relative to the previous case (Figure 15 and Table 3 ). The averaged values from the simulations are shown Table 3 (see Table 3 footnotes for details) and the WVC before convection is close to zero. Similar to FEB06, relative large differences are seen over $15-16 \mathrm{~km}$ where the main convection outflows locate as shown in Figure 15: HOMK and HOMB predict about $25 \%$ lower WVC around 15-16 km relative to HOMH and TOPFZ mainly due to smaller anvil area (transport is not the main reason since the convective

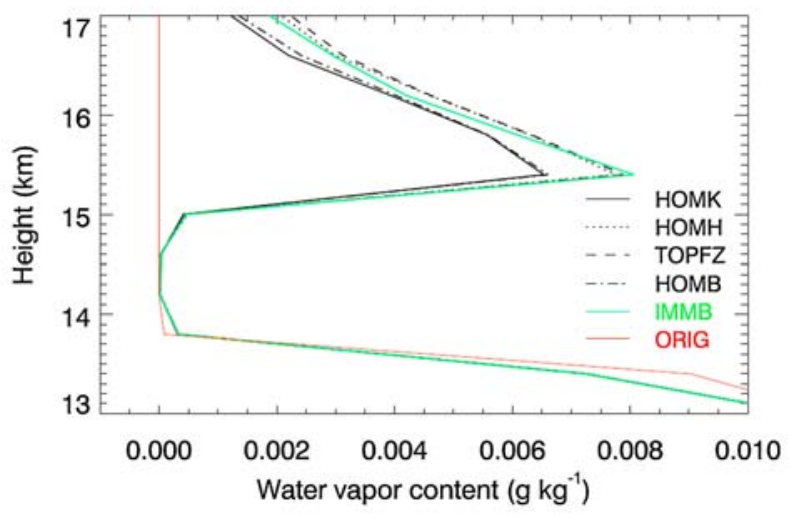

Figure 15. As in Figure 10, but for NOV16 over the $1 \mathrm{~h}$ time period (40-100 $\mathrm{min})$. 
strength in HOMB is similar as HOMH and TOPFZ). Different from FEB06, the BIGG immersion-freezing parameterization (IMMB) does not predict the much higher WVC than any other simulations in this polluted-dry case. Although the WVC is still up to $25 \%$ higher than that in HOMB with the VALI immersion-freezing scheme, it is close to those in HOMH and TOPFZ because of the offset of the effects from weaker convection and relatively larger anvil area.

\section{Conclusions and Discussion}

[39] Two isolated deep convective clouds observed during the TWP-ICE and ACTIVE campaigns have been simulated using a 3-D cloud-resolving model with size-resolved aerosol and cloud microphysics. The TWP-ICE case represents a clean and humid air mass, while the ACTIVE case represents a polluted and dry air mass. The impacts of different homogeneous (i.e., KOOP, HEYM, TOPFZ, and BIGG) and immersion freezing (i.e., VALI and BIGG) parameterizations on the anvil characteristics and the water vapor content of the TTL are examined for these two deep convective clouds that developed in the contrasting environments. The modeled cloud properties generally agree with the available radar and satellite retrievals and in situ aircraft measurements.

[40] Although the homogeneous freezing parameterizations have little impact on the overall convection strength and precipitation, the effects on the anvil microphysical properties are noticeable in both cases. The cloud anvil with the KOOP parameterization has much lower ice particle number concentrations than those with other schemes, and this effect is larger in the polluted-dry case (up to $50 \%$ and $70 \%$ lower in the clean-humid and polluted-dry cases, respectively). This decrease results from the lower droplet freezing rates determined by the KOOP scheme at lower $R H$ and/or for small droplets.

[41] As expected when ice particle number concentrations are smaller, the ice particle effective radius in cloud anvils is increased with the KOOP scheme. On average, the increase is about 20-30 $\mu \mathrm{m}$ relative to the other HomFPs in the both case. The ice particle effective radius by BIGG immersion freezing is reduced by about $40 \mu \mathrm{m}$ compared with that from the VALI scheme. The changes of extinction coefficient at the visible wavelength are also significant in both cases: The KOOP scheme predicts more than $30 \%$ smaller extinction coefficient compared with other HomFPs; the BIGG immersion freezing predicts $50-60 \%$ larger extinction coefficient relative to the VALI scheme. As a result, cloud albedo and radiative forcing of anvils would be significantly affected by the homogeneous and immersion freezing parameterizations applied in the model.

[42] Convective strength in cloud anvils changes within $5 \%$ with different HomFPs in the clean-humid case. The KOOP homogeneous nucleation scheme gives about $15 \%$ lower updraft velocity in the anvils than other HomFPs in the polluted-dry case due to lower freezing rates. Anvil size is determined by the convective strength in the initial $2 \mathrm{~h}$, and its dissipation is determined by ice particle size and upper level convection. With the KOOP scheme in both cases, the anvil size is smaller initially due to relatively weaker convection and the anvil dissipates slowly due to slower evaporation resulted from larger ice particle size.
[43] It is found that the higher immersion-freezing rate (such as BIGG) leads to a stronger convective cloud due to larger latent heat release mainly resulted from much higher freezing rates, with larger ice water path in both humid and dry conditions. Consequently, the domain-averaged homogeneous freezing rates are enhanced by over $15 \%$. This enhancement is consistent with the studies by Heymsfield et al. [2005] and Ekman et al. [2007] that showed an increase in ice nuclei increases the homogeneous nucleation rates through higher updraft velocities. Ice number concentrations in the cloud anvil increase by over 1.5 times and ice particle effective radius is much reduced. Also, higher immersion freezing rate results in less precipitation and larger anvil size. While the higher immersion-freezing rate leads to the stronger upper level convection in the clean-humid case, it makes the upper level convection weaker in the polluted-dry case because of less latent heat release associated with inefficient deposition due to smaller ice particles and the dry condition.

[44] The deep convection moistens the TTL clear air with increases of a few times in WVC under both the clean-humid the polluted-dry conditions. Different HomFPs does not make significant difference in WVC in the clean-humid case, but in the polluted-dry case, the HomFPs with lower nucleation rates (e.g., KOOP and BIGG) predict about $25 \%$ lower WVC relative to the HomFPs with higher nucleation rates (e.g., HEYM) at the altitudes of the main convective outflows relative to other HomFPs mainly due to smaller anvil area (i.e., less cloudy grids) in the domain. Under both humid and dry conditions, the BIGG immersion freezing scheme predicts about $25 \%$ higher WVC relative to the VALI scheme at the altitudes of the main convective outflows, due to stronger transport from the lower levels and the larger anvil area in the domain.

[45] In summary, the anvil microphysical properties such as ice number concentration and ice particle effective radius are sensitive to the homogeneous freezing parameterizations under both the clean-humid and polluted-dry conditions, while the upper level convection and WVC in the TTL clear air are only sensitive to HomFPs under the polluted-dry condition. Higher immersion-freezing rates lead to a stronger convective cloud with much different cloud anvil properties. Also, the domain-averaged homogenous freezing rates are greatly enhanced by the higher immersion-freezing rate under both humid and dry conditions. The HEYM homogeneous freezing scheme predicts similar results as the assumption of freezing probability of 1.0. The effects of different freezing parameterizations on convection and anvil properties shown in this work could be underestimated because of the quick development of convection due to heat bubble effect. Last, the spread in the aircraft observations is so large that it is hard to quantify the cloud anvil properties, which makes it difficult to further constrain model simulations with different freezing parameterizations. We have the following suggestions on the point of how measurements can be used to constrain model results and perhaps to distinguish a better parameterization based on this study: Develop more accurate calibration for CPI measurements, reduce the effects of artificial factors such as shattering from CIP measurements, conduct intensive measurements at $10-13 \mathrm{~km}$ in the tropical deep convective cases, and more accurately retrieve or measure ice particle sizes. 
[46] Acknowledgments. This study was supported by the PNNL Directed Research and Development (LDRD) program as part of the Aerosol Climate Initiative (ACI) by the Office of Biological and Environmenta Research of the U.S. Department of Energy (DE-FG02-02ER63337, DEFG02-07ER64378, and DE-FG02-09ER64770) as part of the Atmospheric Radiation Measurement (ARM) program, the ARM Uninhabited Aerospace Vehicle program (UAV), the ARM Aerial Vehicle Program (AVP), and the ARM Aerial Facility (AAF). The authors are grateful to P. Connolly and A. Bansemer for the ACTIVE aircraft data and help on processing the data, and to J. Um and M. Freer for the help on processing the TWP-ICE data. We also thank S. Xie for the forcing data; M. Khaiyer and Pat Minnis for gridded VISST satellite data; P. May, M. Whimpey, and C. Schumacher for C-POL radar data. Thanks to the ACTIVE and TWP-ICE teams for the data set. This research used compute resources from EMSL, a national scientific user facility sponsored by the Department of Energy's Office of BER located at PNNL. Computer resources from NERSC, which is supported by the Office of Science of DOE, were also used. We greatly appreciate Andy Hemysfield for the code of the KOOP parameterization and the helpful discussion on it.

\section{References}

Allen, G., et al. (2008), Aerosol and trace-gas measurements in the Darwin area during the wet season, J. Geophys. Res., 113, D06306, doi:10.1029/ 2007JD008706

Archuleta, C. M., P. J. DeMott, and S. M. Kreidenweis (2005), Ice nucleation by surrogates for atmospheric mineral dust and mineral dust/sulfate particles at cirrus temperatures, Atmos. Chem. Phys., 5, 2617-2634.

Bigg, E. K. (1953), The formation of atmospheric ice crystals by the freezing of droplets, Q. J. R. Meteorol. Soc., 79, 510-519, doi:10.1002 qj.49707934207.

Connolly, P. J., T. W. Choularton, M. W. Gallagher, K. N. Bower, M. J. Flynn, and J. A. Whiteway (2006), Cloud-resolving simulations of intense tropical Hector thunderstorms: Implications for aerosol-cloud interactions, Q. J. R. Meteorol. Soc., 132, 3079-3106, doi:10.1256/ qj.05.86

Connolly, P. J., et al. (2007), Calibration of the cloud particle imager probes using calibration beads and ice crystal analogs: The depth of field J. Atmos. Oceanic Technol., 24, 1860-1879, doi:10.1175/JTECH2096.1.

Connolly, P. J., G. Vaughan, P. May, P. Minnis, K. Ayers, G. Allen, M. Zhu, and T. Choularton (2008), A study into the effects of aerosols on intense hector thunderstorms in 2005/2006, paper presented at the 15 th International Conference on Clouds and Precipitation (ICCP-2008), Cent de Cienc. de la Atmós., Univ. Nac. Autón. de México, Cancun, Mexico, 7-11 July.

Corti, T., et al. (2008), Unprecedented evidence for deep convection hydrating the tropical stratosphere, Geophys. Res. Lett., 35, L10810, doi:10.1029/2008GL033641.

Crook, N. A. (2001), Understanding hector: The dynamics of island thunderstorms, Mon. Weather Rev., 129, 1550-1563, doi:10.1175/1520-0493 (2001) $129<1550:$ UHTDOI $>2.0$. CO;2.

DeMott, P. J., D. C. Rogers, and S. M. Kreidenweis (1997), The susceptibility of ice formation in upper tropospheric clouds to insoluble aerosol components, J. Geophys. Res., 102(D16), 19,575-19,584, doi:10.1029/ 97JD01138.

Dickerson, R. R., et al. (1987), Thunderstorms: An important mechanism in the transport of air pollutants, Science, 235, 460-465.

Eadie, W. J. (1971), A molecular theory of the homogeneous nucleation of ice from supersooled water, Ph.D. dissertation, 117 pp., Univ. of Chicago Cloud Phys. Lab., Chicago, Ill. (Available as NTIS PB201625 from http://www.ntis.gov.)

Ekman, A. M. L., A. Engström, and C. Wang (2007), The effect of aerosol composition and concentration on the development and anvil properties of a continental deep convective cloud, Q. J. R. Meteorol. Soc., 133, 1439-1452.

Engström, A., A. M. L. Ekman, R. Krejci, J. Ström, M. de Reus, and C. Wang (2008), Observational and modeling evidence of tropical deep convective clouds as a source of midtropospheric accumulation mode aerosols, Geophys. Res. Lett., 35, L23813, doi:10.1029/2008GL035817.

Fan, J., R. Zhang, G. Li, W.-K. Tao, and X. Li (2007a), Simulations of cumulus clouds using a spectral microphysics cloud-resolving model, J. Geophys. Res., 112, D04201, doi:10.1029/2006JD007688.

Fan, J., R. Zhang, G. Li, and W.-K. Tao (2007b), Effects of aerosols and relative humidity on cumulus clouds, J. Geophys. Res., 112, D14204, doi:10.1029/2006JD008136.

Fan, J., M. Ovtchinnikov, J. Comstock, S. A. McFarlane, and A. Khain (2009), Ice formation in Arctic mixed-phase clouds: Insights from a 3-D cloud-resolving model with size-resolved aerosol and cloud microphysics, J. Geophys. Res., 114, D04205, doi:10.1029/2008JD010782.
Frederick, K., and C. Schumacher (2008), Anvil characteristics as seen by C-POL during the Tropical Warm Pool International Cloud Experiment (TWP-ICE), Mon. Weather Rev., 136, 206-222, doi:10.1175/ 2007MWR2068.1.

$\mathrm{Fu}, \mathrm{Q}$. (1996), An accurate parameterization of the solar radiative properties of cirrus clouds for climate models, J. Clim., 9, 2058-2081, doi:10.1175/ 1520-0442(1996)009<2058:AAPOTS >2.0.CO;2.

Fueglistaler, S., A. E. Dessler, T. J. Dunkerton, I. Folkins, Q. Fu, and P. W. Mote (2009), Tropical tropopause layer, Rev. Geophys., 47, RG1004, doi:10.1029/2008RG000267.

Futyan, J. M., and A. D. Del Genio (2007), Deep convective system evolution over Africa and the tropical Atlantic, J. Clim., 20, 5041-5060, doi:10.1175/JCLI4297.1.

Grosvenor, D. P., T. W. Choularton, H. Coe, and G. Held (2007), A study of the effect of overshooting deep convection on the water content of the TTL and lower stratosphere from cloud resolving model simulations, Atmos. Chem. Phys., 7, 4977-5002.

Heymsfield, A. J., and L. M. Miloshevich (1993), Homogeneous ice nucleation and supercooled liquid water in orographic wave clouds, J. Atmos. Sci., 50, 2335-2353, doi:10.1175/1520-0469(1993) $050<2335:$ HINASL $>2.0$. CO 2 .

Heymsfield, A. J., and R. M. Sabin (1989), Cirrus crystal nucleation by homogeneous freezing of solution droplets, J. Atmos. Sci., 46, 22522264, doi:10.1175/1520-0469(1989)046<2252:CCNBHF>2.0.CO;2.

Heymsfield, A. J., L. M. Miloshevich, C. Schmitt, A. Bansemer, C. Twohy, M. R. Poellot, A. Fridlind, and H. Gerber (2005), Homogeneous ice nucleation in subtropical and tropical convection and its influence on cirrus anvil microphysics, J. Atmos. Sci., 62, 41-64, doi:10.1175/JAS3360.1 .

Hume, T. (2007), Radiation dry bias in the TWP-ICE radiosonde soundings, paper presented at the 17 th ARM Science Team Meeting, Monterey, Calif., March. (Available at www.arm.gov/publications/proceedings/conf17/ poster/P00011.pdf)

Jensen, E. J., and A. S. Ackerman (2006), Homogeneous aerosol freezing in the tops of high-altitude tropical cumulonimbus clouds, Geophys. Res. Lett., 33, L08802, doi:10.1029/2005GL024928.

Jensen, E. J., et al. (2005), Ice supersaturations exceeding $100 \%$ at the cold tropical tropopause: Implications for cirrus formation and dehydration, Atmos. Chem. Phys., 5, 851-862.

Jensen, E. J., A. S. Ackerman, and J. A. Smith (2007), Can overshooting convection dehydrate the tropical tropopause layer?, J. Geophys. Res., 112, D11209, doi:10.1029/2006JD007943.

Kärcher, B. (2003), Simulating gas-aerosol-cirrus interactions: Processoriented microphysical model and applications, Atmos. Chem. Phys., 3, 1645-1664.

Keenan, T., K. Glasson, F. Cummings, T. S. Bird, J. Keeler, and J. Lutz (1998), The BMRC/NCAR C-band polarimetric (C-POL) radar system, J. Atmos. Oceanic Technol., 15, 871-886, doi:10.1175/1520-0426 (1998)015<0871:TBNCBP $>2.0$. CO;2.

Khain, A. P., M. Ovtchinnikov, M. Pinsky, A. Pokrovsky, and H. Krugliak (2000), Notes on the state-of-the-art numerical modeling of cloud microphysics, Atmos. Res., 55, 159-224, doi:10.1016/S0169-8095(00)00064-8.

Khain, A. P., A. Pokrovsky, M. Pinsky, A. Seifert, and V. Phillips (2004), Simulation of effects of atmospheric aerosols on deep turbulent convective clouds using a spectral microphysics mixed-phase cumulus cloud model: I. Model description and possible applications, J. Atmos. Sci., 61, 2963-2982.

Khain, A. P., D. Rosenfeld, and A. Pokrovsky (2005), Aerosol impact on the dynamics and microphysics of deep convective clouds, Q. J. R. Meteorol. Soc., 131, 1-25, doi:10.1256/qj.04.62.

Khain, A., N. BenMoshe, and A. Pokrovsky (2008), Factors determining the impact of aerosols on surface precipitation from clouds: An attempt at classification, J. Atmos. Sci., 65, 1721-1748, doi:10.1175/ 2007JAS2515.1.

Khairoutdinov, M. F., and D. A. Randall (2003), Cloud resolving modeling of the ARM summer 1997 IOP: Model formulation, results, uncertainties, and sensitivities, J. Atmos. Sci., 60, 607-625, doi:10.1175/1520-0469 (2003)060<0607:CRMOTA $>2.0$. CO;2.

Kiehl, J. T., J. J. Hack, G. B. Bonan, B. A. Boville, D. L. Williamson, and P. J. Rasch (1998), The National Center for Atmospheric Research Community Climate Model: CCM3, J. Clim., 11, 1131-1149, doi:10.1175/1520-0442(1998)011<1131:TNCFAR>2.0.CO;2.

Koop, T., B. Luo, A. Tsias, and T. Peter (2000), Water activity as the determinant for homogeneous ice nucleation in aqueous solutions, Nature, 406, 611-614, doi:10.1038/35020537.

Kuang, Z. M., and C. S. Bretherton (2004), Convective influence on the heat balance of the tropical tropopause layer: A cloud resolving model study, J. Atmos. Sci., 23, 2919-2927, doi:10.1175/JAS-3306.1. 
Kuhn, T., M. E. Earle, A. F. Khailizov, and J. J. Sloan (2009), Size dependence of volume and surface nucleation rates for homogeneous freezing of supercooled water droplets, Atmos. Chem. Phys. Discuss., 9, 22,929-22,953.

Lin, R. F., D. O. Starr, P. J. DeMott, R. Cotton, K. Sassen, E. Jensen, B. Kärcher, and X. Liu (2002), Cirrus Parcel Model Comparison Project, Phase 1: The critical components to simulate cirrus initiation explicitly, $J$ Atmos. Sci., 59, 2305-2329, doi:10.1175/1520-0469(2002)059<2305: CPMCPP $>2.0 . \mathrm{CO} ; 2$.

Lynn, B. H., A. P. Khain, J. Dudhia, D. Rosenfeld, A. Pokrovsky, and A. Seifert (2005a), Spectral (bin) microphysics coupled with a mesoscale model (MM5): part I. Model description and first results, Mon. Weather Rev., 133, 44-58, doi:10.1175/MWR-2840.1.

Lynn, B. H., A. P. Khain, J. Dudhia, D. Rosenfeld, A. Pokrovsky, and A. Seifert (2005b), Spectral (bin) microphysics coupled with a mesoscale model (MM5): part II. Simulation of a cape rain event with a squall line, Mon. Weather Rev., 133, 59-71, doi:10.1175/MWR-2841.1.

May, P. T., G. Allen, G. Vaughan, and P. Connolly (2009), Aerosol and thermodynamic effects on tropical cloud systems during TWPICE and ACTIVE, Atmos. Chem. Phys., 9, 15-24.

McFarquhar, G., J. Um, M. Freer, D. Baumgardner, G. L. Kok, and G. Mace (2007), Importance of small ice crystals to cirrus properties: Observations from the Tropical Warm Pool International Cloud Experiment (TWP-ICE), Geophys. Res. Lett., 34, L13803, doi:10.1029/ 2007GL029865.

Meyers, M. P., P. J. DeMott, and W. R. Cotton (1992), New primary icenucleation parameterizations in an explicit cloud model, J. Appl. Meteorol., 31, 708-721, doi:10.1175/1520-0450(1992)031<0708:NPINPI $>2.0$. $\mathrm{CO} ; 2$.

Minnis, P., et al. (2006), Large-scale cloud properties and radiative fluxes over Darwin during TWP-ICE, paper presented at the 16th ARM Science Team Meeting, Albuquerque, N. M., 27-31 March.

Morrison, H., J. O. Pinto, J. A. Curry, and G. M. McFarquhar (2008), Sensitivity of modeled Arctic mixed-phase stratocumulus to cloud condensation and ice nuclei over regionally varying surface conditions, $J$. Geophys. Res., 113, D05203, doi:10.1029/2007JD008729.

Murphy, D. M., and T. Koop (2005), Review of the vapour pressures of ice and supercooled water for atmospheric applications, $Q$. J. R. Meteorol. Soc., 131, 1539-1565, doi:10.1256/qj.04.94.

Ovtchinnikov, M., and Y. L. Kogan (2000), An investigation of ice production mechanisms in small cumuliform clouds using a $3 \mathrm{D}$ model with explicit microphysics: part I. Model description, J. Atmos. Sci., 57, 2989-3003, doi:10.1175/1520-0469(2000)057<2989:AIOIPM>2.0. $\mathrm{CO} ; 2$.

Phillips, V. T. J., et al. (2005), Anvil glaciation in a deep cumulus updraught over Florida simulated with the explicit microphysics model: I. Impact of various nucleation processes, $Q$. J. R. Meteorol. Soc., 131(609), 2019-2046, doi:10.1256/qj.04.85.

Reisin, T., Z. Levin, and S. Tzvion (1996), Rain production in convective clouds as simulated in an axisymmetric model with detailed microphysics: part 1. Description of the model, J. Atmos. Sci., 53, 497-519, doi:10.1175/ 1520-0469(1996)053<0497:RPICCA >2.0.CO;2.

Reisner, J., R. M. Rasmussen, and R. T. Bruintjes (1998), Explicit forecasting of supercooled liquid water in winter storms using the MM5 mesoscale model, Q. J. R. Meteorol. Soc., 124, 1071-1107, doi:10.1002/ qj. 49712454804.

Sassen, K., and G. C. Dodd (1988), Homogeneous nucleation rate for highly supercooled cirrus cloud droplets, J. Atmos. Sci., 45, 1357-1367.

Sherwood, S. C., and A. E. Dessler (2000), On the control of stratospheric humidity, Geophys. Res. Lett., 27, 2513-2516, doi:10.1029/ 2000GL011438.

Sherwood, S. C., T. Horinouchi, and H. A. Zeleznik (2003), Convective impact on temperatures observed near the tropical tropopause, J. Atmos. Sci., 60, 1847-1856, doi:10.1175/1520-0469(2003) $060<1847:$ CIOTON $>2.0$. CO 2 .

Shulman, M. L., M. C. Jacobson, R. J. Carlson, R. E. Synovec, and T. E. Young (1996), Dissolution behavior and surface tension effects of organic compounds in nucleating cloud droplets, Geophys. Res. Lett., 23, 277-280, doi:10.1029/95GL03810.

Smith, J. A., A. S. Ackerman, E. J. Jensen, and O. B. Toon (2006), Role of deep convection in establishing the isotopic composition of water vapor in the tropical transition layer, Geophys. Res. Lett., 33, L06812, doi:10.1029/2005GL024078.
Smolarkiewicz, P. K., and W. W. Grabowski (1990), The multidimensional positive definite advection transport algorithm: Nonoscillatory option, J. Comp. Physiol., 86, 355-375.

Stephens, G. L., and S. C. Tsay (1990), On the cloud absorption anormaly, Q. J. R. Meteorol. Soc., 116, 671-704, doi:10.1002/qj.49711649308.

Suortti, T. M., et al. (2008), Tropospheric comparisons of Vaisala radiosondes and balloon-borne frost-point and Lyman- $\alpha$ hygrometers during the LAUTLOS-WAVVAP experiment, J. Atmos. Oceanic Technol., 25, 149-166, doi:10.1175/2007JTECHA887.1.

Svenningsson, B., et al. (2006), Hygroscopic growth and critical supersaturations for mixed aerosol particles of inorganic and organic compounds of atmospheric relevance, Atmos. Chem. Phys., 6, 1937-1952.

Takano, Y., K. N. Liou, and P. Minnis (1992), The effects of small ice crystals on cirrus infrared radiative properties, J. Atmos. Sci., 49, 1487-1493, doi:10.1175/1520-0469(1992)049<1487:TEOSIC >2.0.CO;2.

Tao, W.-K., C.-L. Shie, J. Simpson, S. Braun, R. H. Johnson, and P. E. Ciesielski (2004), Convective systems over the South China Sea: Cloud-resolving model simulations, J. Atmos. Sci., 60, 2929-2956, doi:10.1175/1520-0469(2003)060<2929:CSOTSC >2.0.CO;2.

Tao, W.-K., X. Li, A. Khain, T. Matsui, S. Lang, and J. Simpson (2007), Role of atmospheric aerosol concentration on deep convective precipitation: Cloud-resolving model simulations, J. Geophys. Res., 112, D24S18, doi:10.1029/2007JD008728.

Twohy, C. H., J. W. Strapp, and M. Wendisch (2003), Performance of a counterflow virtual impactor in the NASA icing research tunnel, J. Atmos. Oceanic Technol., 20, 781-790, doi:10.1175/1520-0426 (2003)020<0781:POACVI $>2.0 . C O ; 2$

Tzivion, S., G. Feingold, and Z. Levin (1989), An efficient numerical solution to the stochastic collection equation, J. Atmos. Sci., 44, 3139-3149.

Um, J., and G. M. McFarquhar (2009), Single-scattering properties of aggregates of plates, Q. J. R. Meteorol. Soc., 135, 291-304, doi:10.1002/ qj. 378 .

Vali, G. (1975), Remarks on the mechanism of atmospheric ice nucleation, paper presented at the 8 th International Conference on Nucleation, Leningrad, Russia, 23-29 Sept.

Vaughan, G., et al. (2008), SCOUT-03/ACTIVE: High-altitude aircraft measurements around deep tropical convection, Bull. Am. Meteorol. Soc., 89, 647-662, doi:10.1175/BAMS-89-5-647.

Vömel, H., H. Selkirk, L. Miloshevich, J. Valverde-Canossa, J. Valdes, E. Kyro, R. Kivi, W. Stolz, G. Peng, and J. A. Diaz (2007), Radiation dry bias of the Vaisala RS92 humidity sensor, J. Atmos. Oceanic Technol., 24, 953-963, doi:10.1175/JTECH2019.1.

Wang, C. (2005a), A modeling study of the response of tropical deep convection to the increase of cloud condensation nuclei concentration: 1 . Dynamics and microphysics, J. Geophys. Res., 110, D21211, doi:10.1029/2004JD005720.

Wang, C. (2005b), A modeling study of the response of tropical deep convection to the increase of cloud condensation nuclei concentration: 2 . Radiation and tropospheric chemistry, J. Geophys. Res., 110(D22), D22204, doi:10.1029/2005JD005829.

Wilson, J. W., R. E. Carbone, and J. D. Yuttle (2001), Tropical island convection in the absence of significant topography: part II. Nowcasting storm evolution, Mon. Weather Rev., 129, 1637-1655, doi:10.1175/ 1520-0493(2001)129<1637:TICITA >2.0.CO;2.

Wyser, K. (1998), The effective radius in ice clouds, J. Clim., 11, 17931802, doi:10.1175/1520-0442(1998)011<1793:TERIIC >2.0.CO;2.

Zhang, M. H., J. L. Lin, R. T. Cederwall, J. J. Yio, and S. C. Xie (2001), Objective analysis of ARM IOP data: Method and sensitivity, Mon. Weather Rev., 129, 295-311, doi:10.1175/1520-0493(2001)129<0295: OAOAID $>2.0 . \mathrm{CO} ; 2$.

Zhang, R., G. Li, J. Fan, D. L. Wu, and M. J. Molina (2007), Intensification of Pacific storm track linked to Asian pollution, Proc. Natl. Acad. Sci. U. S. A., 104, 5295-5299, doi:10.1073/pnas.0700618104.

G. Allen, School of Earth, Atmospheric and Environmental Sciences, University of Manchester, Manchester M13 9PL, UK

J. M. Comstock, J. Fan, S. A. McFarlane, and M. Ovchinnikov, Department of Climate Physics, Pacific Northwest National Laboratory, Richland, WA 99352, USA. (jiwen.fan@pnl.gov)

G. McFarquhar, Department of Atmospheric Sciences, University of Illinois at Urbana-Champaign, Urbana, IL 61801, USA. 